\title{
Acquisition of Forest Attributes for Decision Support at the Forest Enterprise Level Using Remote-Sensing Techniques-A Review
}

\author{
Peter Surový * and Karel Kuželka \\ Faculty of Forestry and Wood Sciences, Czech University of Life Sciences, Prague, Kamýcká 129, 16500 Praha, \\ Czech Republic; kuzelka@fld.czu.cz \\ * Correspondence: surovy@fld.czu.cz; Tel.: +42-022-438-3871
}

Received: 10 February 2019; Accepted: 15 March 2019; Published: 19 March 2019

check for updates

\begin{abstract}
In recent decades, remote sensing techniques and the associated hardware and software have made substantial improvements. With satellite images that can obtain sub-meter spatial resolution, and new hardware, particularly unmanned aerial vehicles and systems, there are many emerging opportunities for improved data acquisition, including variable temporal and spectral resolutions. Combined with the evolution of techniques for aerial remote sensing, such as full wave laser scanners, hyperspectral scanners, and aerial radar sensors, the potential to incorporate this new data in forest management is enormous. Here we provide an overview of the current state-of-the-art remote sensing techniques for large forest areas thousands or tens of thousands of hectares. We examined modern remote sensing techniques used to obtain forest data that are directly applicable to decision making issues, and we provided a general overview of the types of data that can be obtained using remote sensing. The most easily accessible forest variable described in many works is stand or tree height, followed by other inventory variables like basal area, tree number, diameters, and volume, which are crucial in decision making process, especially for thinning and harvest planning, and timber transport optimization. Information about zonation and species composition are often described as more difficult to assess; however, this information usually is not required on annual basis. Counts of studies on forest health show an increasing trend in the last years, mostly in context of availability of new sensors as well as increased forest vulnerability caused by climate change; by virtue to modern sensors interesting methods were developed for detection of stressed or damaged trees. Unexpectedly few works focus on regeneration and seedlings evaluation; though regenerated stands should be regularly monitored in order to maintain forest cover sustainability.
\end{abstract}

Keywords: remote sensing; forest enterprise; forest attributes; forest health; satellite imagery; aerial imagery; aerial laser scanner; unmanned aerial vehicles (UAV)

\section{Introduction}

The forest management, in a simplified form, can be understood as human interaction with forest ecosystems with the purpose of providing goods and benefits for society and at the same time protecting as much as possible the ecosystem itself. The idea for sustainable management is to maintain the income of goods for people, including production of wood, bark, and resin, together with preserving non-productive functions like water infiltration, biodiversity protection, and aesthetic value over time.

The activities of forest management comprise a complex rational process that consists of three consequential chain links, so called three Ds: Data, Dynamics, and Decisions. What practitioners do are 
the decisions; however, no reasonable decision can be taken without information background based on recent data. In forestry and related nature management fields, the second link of the management chain, i.e., Dynamics, is crucial for the good decision making practices as well, because forest is a long term ecosystem (in contrast to agriculture crops for example) usually overpassing the human life span. In other words, for good management decision, it is necessary to know in detail both the recent state of the forest ecosystems in the territory and their future development without any human interference or with planned management interventions [1].

Recent advances remote sensing, computer vision, and other related research fields created many opportunities for practical forestry to facilitate and improve data gathering in terms of precision, accuracy, but also in the possibilities of creating more detailed temporal and spatial resolution datasets. Several reviews summarized different aspects of the recently emerged opportunities and showed the advantages of remote sensing techniques as a tool for enhancing forest inventories [2,3] or one specialized aspect of inventory data such as species classification [4] or heath status [5-7]. Other reviews evaluated possibilities of different types of sensors [8] or carriers [9,10].

In this review, we focus on methods providing data that can be of interest for managers of medium-size forest enterprise. The term forest enterprise is understood here as an enterprise managing forests in with an approximate area measured in thousands to tens of thousands of hectares of forest stands, without any management restrictions (i.e., excluding national parks), and with common aims of management. We focus on central European forestry conditions, which are very well known for the authors.

During writing the paper, we consulted the information requirements for decision-making with several forest enterprise management members. As a result, we describe how information needs in decision-making either can be saturated by recent discoveries in remote sensing, or how they could become supported in short time, based on the recently published promising results.

According to the discussion with forest managers, information needs for decision-making in forest enterprise may be grouped into following sections:

- Mapping of geometrical borders of compartments that can be also understood as delineation of homogeneous areas or so called stratification (the utilization of the term stratification here is not to be confused with vertical stratification). This also includes pre stratification in inventory, or delineation of windthrow and salvage logged areas.

- Mapping regeneration or succession in stands where no (or minimum) presence of adult trees exists.

- Assessing height of the forest population on either stand or individual tree level.

- Assessing other inventory parameters like diameter at breast height (DBH), basal area, and volume (stock).

- $\quad$ Species classification or assessment of dominant species in forest stands.

- $\quad$ Assessing the tree health status and mortality (induced by any factor).

We utilized ISI web of Knowledge search engine and Google scholar search engine for assessment of individual keywords from this list or in combination with carrier required to evaluate (e.g., satellite, airplane, or unmanned aerial vehicles (UAV)) because we wanted to give here full overview of remote sensing possibilities from all aspects and resolution.

\section{Major Breakthroughs in Hardware and Data Processing}

In this section, we describe briefly the recent breakthrough and discoveries that significantly improved the remote sensing technology and applications. There often are several options for satisfying specific information needs, varying in level of detail, accuracy, work difficulties, and costs. For the forest manager, it is important to consider individual options to select the optimal solution for a given situation. 


\subsection{Carriers and Sensors}

We describe three important sensor carriers, which typically correspond with three levels of details of acquired data: satellites providing data with coarsest resolution and largest spatial extent, airplanes being the halfway solution, and drones representing ultrahigh resolution of data over a local spatial extent; with possible overlap of data resolution in dependence of application and utilized sensors.

Satellite technology beginnings are dated back to year of 1957 when first satellite called Sputnik was launched to the space. First applications of satellite data for forestry purposes (or imagery utilizable for forestry purposes) can be dated to somewhere in the 1980s with first works like [11] focusing on strata finding using coarse resolution satellites Landsat. Large scale (coarse resolution) satellites were evaluated for different purposes as described in following chapter, but probably the significant change came with very high resolution satellites (VHR) as IKONOS satellite launched in 1999 with spatial resolution 1 meter and 4 meters for panchromatic and multispectral bands, respectively. Many other satellites with VHR were launched since that period, for example: WorldView-1, -2 , and -3 , Ziyuan-3A, Pléiades, RapidEye, QuickBird, GeoEye-1, and recently so-called micro satellites available for example from Planet Labs, Inc. (https:/ / www.planet.com/). Forestry practitioner can expect very high-resolution data approximately 0.5 meter in panchromatic and 2 meters in multispectral practically every day (as claimed by Planet Labs, Inc.).

Manned airplanes are a traditional carrier for remote sensors. First attempts to acquire forest attributes from aerial imagery took place several decades ago [12] and since that airplanes served as an important source of data for forest decision, providing not only visual red-green-blue (RGB) aerial imagery, but later multispectral, hyperspectral, radar, or laser data.

The most significant novelty of the last approximately 15 years in the field of remote sensing is the appearance and rapid development of unmanned aerial vehicles (UAV), unmanned aerial systems (UAS), or remotely piloted aerial systems (RPAS) generally called drones. They rapidly become a valid alternative for traditional sensor carriers, especially for detailed investigation over a small area and found a wide spectra of applications [10,13]. Due to further development of the carriers as well as sensor miniaturization, the UAVs could soon serve as carriers of many types of sensors, from ultra-high resolution RGB cameras, over special lightweight hyperspectral sensors [8] to lightweight laser scanners adopted for the use on UAVs $[14,15]$. An opportunity for new precise applications of UAVs was the improved positioning with the use real-time kinematics (RTK) global navigation satellite system (GNSS) positioning $[16,17]$ that allows record the actual position of the carrier and the acquired data with centimeter-level accuracy.

\subsection{Processing Techniques}

Apart of sensors and careers, important breakthroughs were achieved in image processing and raster analysis, which helps automatic (unsupervised) or semiautomatic (supervised) analysis of large-scale data. In the coarse resolution remote sensing data the most important probably can be deployment of modern statistical methods namely Random Forest, Support Vector Machine, and convolutional neural networks (in individual works it will be cited later). Random Forest is classification and regression technique operating on multiple decision trees providing final attribution of the object (pixel, segment) into predefined class, similarly Support Vector Machine is based on non-probabilistic binary linear classifiers. Convolutional Neural Networks are dedicated mostly to image analysis; they work on different self-defined filters which allow creation of point based network simulating neuron connections in human brain, making then the final decision about attribution of image to certain category or class.

The second important breakthrough is the enormous evolution of Structure from Motion (SfM) technique, which allows a fully automatic reconstruction of 3D scenes and photogrammetric point clouds from overlapping images without precalibration or human intervention. The most significant utilization of this technique is generation of point clouds representing the canopy cover, which serves as a suitable source for canopy height model derivation or individual crown delineation. 


\section{Methods of Forest Properties Assessment}

In this section, we describe individual remote sensing methods applicable for operational forest inventories and monitoring in forest enterprises. First, we focus on geometrical or structural properties of the forest describing the 3D structure of trees and stands. Among those properties we describe above all: zones and strata of forests (automatic or supervised division of the forested area into homogeneous units which can serve as a base for future inventory and management actions), detection of regeneration (mostly focused on regeneration presence as binary variable: present and not present), canopy height estimation (the height of canopy or height of individual trees), individual tree delineation (finding individual trees either by direct delineation or by area based statistical approaches), diameter or in coarser scale basal area (in coarse scale images where individual trees are not visible basal area is a reasonable proxy to the diameter), canopy closure (stocking which also includes gaps delineation), and finally the growing stock (volume and biomass assessment). Secondly, we describe approaches utilizing spectral properties of forest stand and trees. Spectral behavior is mainly used in tree species classification and forest health assessment. However, more and more works, namely in context with developing complex algorithms, structural and spectral properties of forest trees and stands are handled simultaneously and applications utilizing only spectral or only structural information occur rarely.

The chapter is divided into three subsections corresponding with three levels of details of acquired data corresponding to the three most important remote sensing sensors carriers, i.e., satellites, airplanes, and unmanned aerial vehicles. Within each subsection, described works are classified according to applications and target variables. Numbers of works that have been summarized in this review according to sensor carrier and application are provided in Table 1.

Table 1. Numbers of works summarized in this review according to sensor carrier and application.

UAV: unmanned aerial vehicles.

\begin{tabular}{cccccccc}
\hline & Stratification & Regeneration & Individuals & Height & Inventory & Species & Health \\
\hline Satellite & 7 & 3 & - & 6 & 8 & 7 & 9 \\
Airplane & 5 & 7 & 19 & 12 & 25 & 13 & 5 \\
UAV & - & 3 & 10 & 12 & 12 & 10 & 13 \\
\hline
\end{tabular}

\subsection{Satellite Data}

For geometrical purposes on the level of forest enterprise, the best option may appear to be very high resolution (VHR) satellite imagery, because of relatively small distances from wall to wall (as referred in literature) e.g., areas that are filled with relatively closed or continuous canopy. Very high resolution in satellite data refers to resolutions from $5 \mathrm{~m} /$ pixel up to $30 \mathrm{~cm} /$ pixel. The main usage of VHR data is estimation of growing stock together with other geometrical descriptors of forest canopy like height, crown size etc. Along with the articles focusing on VHR, there is also a set of works utilizing large spatial resolution pixels, especially based on Landsat and Sentinel missions.

It seems that the potential of VHR satellite images is not yet fully exploited. Fassnacht et al. [18] show that applications of VHR satellite stereo-imagery from WorldView-2 cover a wide spectrum reaching from estimating stand density and biomass to species classification with accuracies approaching those achieved using aerial hyperspectral and LiDAR data. Considering the broad application potential, simplicity of data acquisition and processing, and reasonable price, VHR satellite data may represent a very suitable data for supporting operational forest inventories.

\subsubsection{Stratification}

The first topic where remote sensing in larger scale can be easily deployed is stratification, e.g., finding equal or similar areas in the forest land which can serve for more efficient and time saving sampling designs and inventory work. In central European conditions most of the managed forests are 
already stratified by previous spatial division into so called stand divisions, stands and compartments, based on different conditions including ownership, geographic relief, and other environmental factors. Though, as pointed out by Wallner et al. [19], the current trends in society push towards abandonment of monocultures and area based harvesting (clear cuts) what requires more precise and effective ways for inventory and monitoring.

The remote-based stratified sampling related to forest inventory was probably first time described by Poso et al. [11] who investigated coarse resolution satellite Landsat-3 with pixel size approximately 80 meters and 4 spectral bands (red, green, blue, and near infrared) for delineation of compartments based on field data and spectral data from satellite. This work was later developed further in Poso, Paananen and Markku. [20] using Landsat 5 Thematic Mapper images. Other stratification approaches indirectly (not solely) utilizing satellite imagery in combination with forest inventory data were [21,22] where the k-Nearest Neighbor technique (kNN) was used as classifier.

Closely related topic is the delineation of zones affected by an extensive change, e.g., deforestation or disturbances. Delineation of such zones can be based on height changes or chlorophyll content evaluation. For example Elatawneh et al. [23] described utilization of two German satellite systems TerraSAR-X (TS-X) and RapidEye (RE) for purpose of the fast mapping of zones affected by windthrow in Bavarian forest national park. The authors described 11 weeks difference in aerial imagery processing in comparison to satellite imagery processing (in favor of satellites). From more recent works [19] utilized RapidEye data for examination of remotely sensed data at enterprise level for prestratification sample plot allocation in the planning stage of forest inventories in heterogeneous forest. The work was motivated with ongoing change from monoculture forestry towards mixed forests where inventory is becoming more difficult, but none the less important. The authors proved $28 \%$ decrease in sampling plots amount (with equal targeted standard error) when compared to systematic sampling.

\subsubsection{Plantations and Succession Monitoring}

From the perspective of forest enterprise, the next step after detecting and delineating similarity zones would be to search for vegetation status or status change inside these zones starting with either small trees or successive vegetation. In general, the task to detect small trees or regeneration is hardly achievable by optical imagery from satellites and in practice most of this kind of work is executed using airplane imagery (or LiDAR data) or more recently drone imagery, however some results are available also for satellite level. Bergen and Dronova [24] described possibilities of multi-temporal Landsat ETM+ imagery for assessment of succession status in aspen dominated forests. The work was divided into two stages: in the first stage the area was divided into forest cover types, in second stage the succession was detected in aspen dominated forest stands using different bands of Landsat ETM+ to distinguish whether the aspen stands are succeeding to conifers or deciduous understory. Another work [25] utilized Landsat TM and Landsat ETM+ for evaluation of so called forest transition (the reversal from deforestation to forest increase). The work was carried out in Carpathian mountain arc comprising four countries (Czech Republic, Poland, Slovakia, and Ukraine). The study, however, was not solely dependent on remote sensed data, but historical paper maps were used as starting point to compare with the current status. Unfortunately, this procedure can be utilized only in case that such ancillary data exists.

Probably the most recent work [26] can be considered as a useful and promising tool for monitoring of either regenerated, either windthrow affected areas for natural regeneration and succession. The authors developed a pixel-based classification of Sentinel-2A images with the aim to recognize automatically forested (includes shrub overgrown) areas. Results of automatic pixel based classification was evaluated as $98.47 \%$ accurate when compared to manual delineation of aerial imagery. Another recent work [27] showed the possibility of mapping small plantations inside forested regions deploying Sentintel-2 images and Random Forest method achieving median overall accuracy larger than $95 \%(95.5 \%-96.0 \%)$ against independent test data. 


\subsubsection{Forest and Tree Height Assessment}

Typical forest (or canopy) height assessment methods from satellites are based usually on radar, laser data or optical data (latter mostly being very high resolution (VHR)). Radar based height assessment was demonstrated in [28] where authors evaluated TandemX radar data for assessment of forest height but not in individual tree level, but in so-called spatial average mostly corresponding to the h100 (average height of one hundred tallest trees). The data were compared to LiDAR based data and in a 56 meter spatial resolution per pixel, authors reported $2.9 \mathrm{~m}$ RMSE with R-square $=0.75$.

Good examples of studies estimating forest height from satellite-borne LiDAR are the works [29] or [30]. In Lefsky et al. [29], data from Geoscience Laser Altimeter System (GLAS) carried on board of Ice, Cloud, and land Elevation Satellite (ICESat) served for forest height estimation in Brazil, Tennessee and Oregon with 68 to $69 \%$ of variance explained and RMSE between $4.85 \mathrm{~m}$ and $12.66 \mathrm{~m}$. In [30] the same system was used and reached RMSE of $6.1 \mathrm{~m}$ and $4.4 \mathrm{~m}$ for field height and modelled height, respectively.

Forest height can efficiently be estimated from coarse resolution satellite imagery as evidenced a recent work of Staben, Lucieer, and Scarth [31] where authors deployed modern statistical techniques of machine learning algorithms to extract data from combination of Landsat TM, ETM+, and OLI satellites and train Random Forest algorithm for estimation of LiDAR based height measurements. They reported RMSE of $2.9 \mathrm{~m}$ and $2.5 \mathrm{~m}$ for mangrove and eucalyptus forests and R-square of 0.49 .

Typical example of height assessment using VHR data is [32] where authors compared three types of IKONOS stereo derived digital surface models (DSMs) that were subtracted by National Elevation Data (NED) digital terrain models (DTMs). The authors proved G-LiHT DSMs and IKONOS DSMs had R-squares larger than 0.84 and RMSEs in the interval of 2.7 to $4.1 \mathrm{~m}$. They suggested that IKONOS-derived canopy height models (CHMs) are good LiDAR alternative when high quality DTMs are available. VHR imagery from one of the most recent satellites Pleiades for canopy height estimation was used in the study [33]. The authors utilized LiDAR data as ground truth validation data and compared tri-stereo and from each stereo pair combination and different viewing angles when three stereo pairs were acquired with one-day offset. They found that average height median difference between these two datasets (laser and satellite) was $0.02 \mathrm{~m}$ and $0.32 \mathrm{~m}$ with standard deviation of 1.9 $\mathrm{m}$ and $3.79 \mathrm{~m}$, respectively. Mostly large cross-track angle was found to reduce the error an overview is shown in Table 2.

Table 2. Accuracies of methods for estimating forest height from satellite data. VHR: very high resolution.

\begin{tabular}{cccc}
\hline Study & Method & RMSE & $\boldsymbol{R}^{\mathbf{2}}$ \\
\hline$[28]$ & Radar & $2.9 \mathrm{~m}$ & 0.75 \\
{$[29]$} & LiDAR & $4.85-12.66 \mathrm{~m}$ & 0.68 \\
{$[30]$} & LiDAR & $6.1-4.4 \mathrm{~m}$ & 0.49 \\
{$[31]$} & Low resolution imagery & $2.5-2.9 \mathrm{~m}$ & 0.84 \\
{$[32]$} & VHR stereo imagery & $2.7-4.1 \mathrm{~m}$ & $0.02-0.32 \mathrm{~m} \pm 1.9-3.79 \mathrm{~m}$ (mean $\pm \mathrm{SD})$ \\
\hline$[33]$ & VHR tri-stereo imagery & . & \\
\hline
\end{tabular}

\subsubsection{Assessing Inventory Attributes}

Most of the works where satellites data were deployed for estimation of other variables than height only usually evaluate all the rest of the inventory (taxation) variables like tree number, diameter, basal area, volume, and biomass. These values are estimated both from geometrical data (texture, textural indices), and from spectral data (reflectance and reflectance indices), and final from the combination of both data types. Models for canopy height and biomass estimation form satellite spectral indices can be validated using CHM-derived from airborne LiDAR data [34].

Moderate and low spatial resolution satellite imagery was used for example in [35] where the authors showed that spectral data with the coarse spatial resolution can estimate the forest structure with error of $30 \%$ in height and larger error for volume and basal area. According to [36] this study 
and other similar ones suggest that coarse resolution optical data cannot (is not recommended to) be utilized at level required for example for operational forestry (e.g., operational forest inventory). So approximately from 2004, works can be found utilizing VHR imagery for forestry purpose [37].

Highly interesting for forest enterprise purposes can be considered one of the first works utilizing VHR imagery for estimating forest attributes [38]. Ikonos 2 and Quickbird imagery was used for assessment of five main forest variables: age, top height, circumference, stand density, and basal area in Norway spruce plantations in Belgium. Norway spruce can be considered as currently dominating species in managed forests in central Europe. In this paper 168 texture features and 5 spectral features were tested as independent (explanatory variables) evaluated with those mentioned five dependent forest variables on 29 measured plots. Reported errors of estimation were of $10 \%$ for top height, 15\% for circumference, $16 \%$ for basal area, $18 \%$ for age, and $29 \%$ for stand density.

Shamsoddini, Trinder, and Turner [36] utilized WorldView-2 satellite imagery, which was launched in October 2009 deploying all 9 available bands from panchromatic with resolution of 0.5 meter through visible and NIR1 and NIR2 with 2 meters resolution. They tested number of vegetation indices, individual bands reflectance, ratios, and so called grey-level co-occurrence matrix (GLCM) textural descriptor. They achieved R-square values of 0.8 for height estimates and approximately 0.4 for basal area and volume (as the lowest accuracy), $8 \%$ of error estimation for height and $30 \%$ error estimation for stand volume.

In 2008 Quickbird was utilized for estimation of crown area of juniper forests by Ozdemir [39] the volume estimated was with R-square of 0.51 and with error of $15.2 \%$. Immitzer [40] described utilization of WorldView-2 satellite for estimation of growing stock in forest enterprise level from wall to wall. They proved that inclusion of spectral data helps the accuracy of growing stock estimation. The overall accuracy was estimated to be with RMSE 15\% and R-square of 0.56 at stand level, slightly lower accuracy was obtained for plot level (RMSE $=34 \%$, R-square $=0.44)$.

\subsubsection{Species Classification}

Recent overview of technologies for classification of species and comparison of different sensors can be found in [41]. The author pointed out that multispectral satellite imagery do not provide complete separation of different species. In his study spectral signatures for stone pine, has been measured by spectroradiometer ASD FieldSpec 4 Hi-Res with an accuracy of $1 \mathrm{~nm}$ and compared to different satellite imagery including hyperspectral Hyperion, hyperspectral CHRIS-Proba, Advanced Land Imager (ALI), and Landsat 8. The best results were achieved using Hyperion with overall accuracy $92 \%$, precision $97 \%$, and Kappa coefficient 0.74 .

Not directly related to forest enterprise but perhaps worth of consideration is recent study on modern high-tech methods [42], where authors used multispectral RapidEye optical imagery for classification of wetland and obtained impressive accuracy of $96.17 \%$ using InceptionResNetV2 very deep convolutional network, in comparison with $74.89 \%$ and $76.08 \%$ when using Support Vector Machine and Random Forest respectively. Tree species classification was evaluated using Pléiades data in [43], classification of seven species using multilevel classification. They concluded that late April was the best season for species classification and achieved average accuracies from $36.13 \%$ to $61.6 \%$ of classification. Liu et al. [44] presented a satellite based classification using freely available satellite imagery Sentinel-2A (S2), Sentinel-1A (S1) in combination with Shuttle Radar Topographic Mission Digital Elevation (DEM) and multi-temporal Landsat-8 images (L8). Another recent case study deploying Sentinel-2 images for classification of forest species is [45], where authors applied supervised pixel-based classifications with a Random Forest classifier. Authors utilized additional 3D data from LiDAR scans and photogrammetry points which improved the results, they tried to classify 11 dominant tree species and reported the overall accuracy of $88.9 \%$. Accuracy and impact of radiometric resolution of satellite data was studied in [46], where authors pointed out that higher radiometric resolution sometimes leads to higher accuracy of results ( $8 \%$ in average) however they noted that it is not always the case and one has to consider also the impact of higher resolution on 
data storage demands. The authors of one of the recent works [47] utilized multi-temporal Sentinel 2 datasets to automatically classify 5 common species in Sweden (Norway spruce, Scots pine, Hybrid larch, Birch, and Pedunculate oak) and achieved an average accuracy of $88.2 \%$ ranging for individual species from $70.9 \%$ to $95.6 \%$.

\subsubsection{Assessing Forest Health and Physiology Status}

Huge part of remote sensing research effort was dedicated to assessment of forest health using satellites and it would be impossible to cite all and not even a significant part of these works. Recently an extensive and deep overview of remote sensing possibilities for forest health assessment was published in series of three large review papers: [5-7]. In the first out of the series [5], authors introduced the concept of spectral traits (ST) and spectral traits variation (STV) and showed how these can help detect forest health and stress status. The article reviewed impressive 497 papers related to the field. In second part of the series [6] the approaches and data models were described, pointing out that mostly linking in-situ and remote sensing approaches may help to understand relationship between stressors, and the associated spectral responses. In this article 253 papers were reviewed and cited. Finally, the third article of the series, published just recently within a larger group of authors [7], reviewed 247 related papers and established requirements for multisource forest health monitoring citing: (1) necessity to understand the effects of multiple stressors on forest health; (2) usage of remote sensing (RS) approaches to monitor forest health; (3) coupling of different monitoring approaches; (4) usage of data science as a bridge between complex and multidimensional big forest health data and (5) a future multi-source forest health monitoring network.

Very interesting work for forest practitioners may be considered [48], where it was presented nearly real time monitoring of forest outbreak in alpine birch forests based on MODIS derived NDVI. The authors reported that $74 \%$ of the defoliation was detected with a misclassification of undisturbed areas of $39 \%$ in those pixels where at least $50 \%$ birch forest cover was present. SPOT-5 images were investigated for forest health in [49], the authors acquired several structural indicators from these images and defined forest health indicator from them. The final forest health indicator was evaluated with RMSE of 1.674 and R-square of 0.47 . From recent articles a study on defoliation of pine stands was presented in [50] where authors evaluated possibility of Sentinel 2 vegetation indices for assessment of this defoliation with several machine learning algorithms (kNN, Random Forest, and Support Vector Machines) obtaining the accuracy of $12.2 \%, 11.9 \%$, and $11.6 \%$ respectively with R-square values of 0.53 , $0.57,0.57$.

Detection of dead trees may be important for forest practitioner especially with respect to bark beetle attacks, when abandoned trees (dead-dry trees) may indicate close presence of the beetle near to these trees. Dead trees detection through satellite imagery was described for example described in [51] or more recently in [52]. Hart and Veblen [51] utilized a National Agriculture Imagery Program (NAIP) for training the Landsat Climate Data Records (LDCR) dataset and reported that on tree level the red-green index was higher for grey attacked trees and on stand level index the decrease (lower values) of NDVI could be noticed. Overall accuracy reported was over $88 \%$. Byer and Jin [52] also deployed Random Forest algorithm for classification and regression producing accuracy of $96.3 \%$ for the classification Random Forest and a RMSE of 7.19 dead trees per acre for the regression Random Forest. Relatively innovative approach was presented by Baker et al. [53], where the authors mapped dead trees attacked by pine beetle by assessing MODIS time series with continuous snow cover, when gaps were used to detect continuous ground snow coverage and a snow-free overstory, and so to detect pixels with crown mortality. The method was tested on 25 high mortality sites and the significance of the model was presented with $\mathrm{p}$ value of 0.03 . In another recent study on oak decline (mortality) using NDVI from Sentinel 2 images, Recanatesi et al. [54] applied Normalized Difference Vegetation Index (NDVI), using the diachronic images provided by the Sentinel-2 satellite to quantify forest health conditions, they reported $5.5 \%$ decrease in vegetative capability. 


\subsection{Aerial Data}

Remote sensing data acquired from manned aircraft can be a very efficient way for monitoring forest attributes at forest enterprise level. Typical area of forest enterprise can be effectively covered with aerial data during one flight of a manned aircraft and at the same time, the area is large enough to benefit from increased efficiency of forest inventories using remote sensed data in comparison to field-based observations.

In the last decade, most attention was paid to utilization of aerial laser scanner (ALS) data and, to a lesser extent, to digital aerial photogrammetry (DAP) utilizing principles of stereophotogrammetry or multi-view photogrammetry [55]. Both methods typically result in 3D point clouds representing the surface of terrain and other objects, such as trees. Due to different nature of data origin, DAP and ALS data embody different properties. DAP data are able to represent accurately and with very high point density the upper canopy envelope whereas ALS data show more capability to capture sub-canopy forest structure. Therefore variables modeled from canopy height (e.g., height, diameter) can be accurately calculated from both DAP and ALS data, whereas variables reflecting the forest structure (e.g., basal area, volume, biomass) may be predicted more accurately using ALS [56]. Number of comparative studies [57-61] show that forest attributes extracted from canopy metrics using area-based approach are very similar for both ALS and DAP data with the highest difference in RMSE\% reaching about $5 \%$ [61]. In contrast, detection of forest canopy gaps gives significantly different results if performed over ALS and DAP data. White et al. [62] illustrate that ALS was able to identify 16 times more gaps and 6.5 times more gap area than DAP. For this specific application, ALS show markedly superior accuracy.

The main advantage of ALS data is the ability to create a detailed DTM even under forest canopies. In some cases such as in stands with high-density canopies, DAP data need to be supported with an accurate DTM as a reference for deriving a correct canopy height model $[63,64]$. On the other hand, Pulliti et al. [60] and White et al.[65] highlighted the effectivity of photogrammetric data for forest inventories: photogrammetric data are typically cheaper and, unlike ALS, provide the spectral component including species-specific information, health or phenological status.

\subsubsection{Stratification}

Aerial imagery can represent a suitable tool for stratification of forest areas leading to improved accuracy of estimates of forest attributes. For example, Holopainen and Wang [66] deal with developing a calibration method of aerial images for forest stratification and with optimizing strata size. However, in recent works, the stratification attempts focus on ALS data. Maltamo et al. [67] examined the effect of aerial imagery-based stratification according to dominant tree species and stand development stage on accuracy of estimates of species-specific forest attribute estimates, especially species-specific volume. They concluded that stratification based on aerial imagery interpretation did not improve the accuracy of estimates due to stratification errors. However, they achieved a slight improvement of accuracy of forest attributes estimates, especially volume of the dominant tree species (improvement $2.6 \%$ ) when stratification using canopy height based on ALS data was applied. When strata representing spruce or pine-dominate stands were created using aerial imagery, accuracy of volume prediction was improved by $73 \%$ and worsened by $13 \%$ for pine and spruce, respectively.

McRoberts, Gobakken, and Næsset [68] tested whether stratification based on ALS-derived volume information can improve accuracy of volume and proportion of forest area predicted from NFI field data. They demonstrated that the accuracy of volume predictions could be improved by factors 2-3.2, while variances of mean proportion of forest area could be reduced by factors up to 1.5. Efficiency of ALS-based stratification was demonstrated for aboveground biomass prediction [69] and for aboveground biomass temporal change prediction [70] where ALS-based stratification helped to reduce standard errors of prediction by $18 \%-84 \%$ compared to pure field survey. Most recent work for delineation of homogeneous zone can be found in Bruggisser et al. [71], where authors proposed an 
automatic framework for delineation of forest patches with homogeneous canopy height structure and with similar water conditions using $k$-means clustering method.

\subsubsection{Plantations and Succession Monitoring}

Both high-resolution aerial imagery and ALS provide sufficient level of detail allowing assessment of coverage or even detection of individual trees in forest natural or artificial regeneration. Utilization of aerial imagery for individual tree detection and crown delineation of conifer forest regeneration was described by Pouliot et al. [72]. They applied trend-change-detection algorithms on local transects that are directed from a potential tree apex. In simple conditions of spruce and pine plantations with a constant spacing of $1 \mathrm{~m}$, the approach achieved the accuracy of $91 \%$.

A similar challenge represents detection of individual small trees in forest tundra. Gobbaken et al. [73], Hauglin and Næsset [74], and Stumberg et al. [75] performed experiments evaluating possibilities of detection and size estimation of individual small trees from ALS data. They utilized different approaches, such as unsupervised classification of tree and non-tree raster cells [75] and concluded that the detection rate depends on height and crown diameter of trees, on ALS point density or raster cell size. However, almost every tree exceeding a height of $1 \mathrm{~m}$ was successfully detected.

Forest regeneration can be successfully detected even in the understory as demonstrated by Yao, Krzystek, and Heurich [76]. They developed a method for detecting individual trees in forest understory by partitioning ALS point cloud which allowed detection of up to $53 \%$ of the trees in the lowest forest layer. Amiri et al. [77] estimated regeneration coverage in multilayered forest using ALS data. The two-step method incorporating mean shift clustering and normalized cut algorithm led to $70 \%$ accuracy of forest regeneration coverage detection. As could be expected, the accuracy was negatively influenced by overstory canopy density and as well by increased proportion of broadleaved species in overstory.

\subsubsection{Individual Tree Segmentation}

Automatic segmentation of individual trees (incorporates individual tree detection and crown delineation) can be performed using structural information in 3D point clouds or spectral information in RGB, multispectral or hyperspectral imagery. Different image analysis algorithm were developed to detect individual trees in single aerial images [78], however, tree detection methods utilizing 3D structural information achieve higher detection rates than methods analyzing the spectral information [79].

Most of the algorithms for individual tree segmentation in 3D data derived from ALS or DAP rely on an accurate canopy height model (CHM) which might be difficult to acquire in very dense forest stands or in a steep terrain. Duan et al. [80] indicate that simple subtracting DTM from DSM in a steep terrain may cause considerable error in CHM and they propose a method for correcting terrain-caused CHM errors based on individual tree crown delineation. In contrast, Ørka et al. [81] conclude that the terrain effect for forest attribute prediction seem to be negligible. In stands with continuous canopies, the penetration of laser beams can be poor causing problems with generating accurate digital terrain model resulting in overestimation of ground elevation [82]. Such situation requires a special algorithm for a correct extraction of DTM [83].

Number of algorithms for individual tree segmentation were developed: watershed algorithm, region growing algorithm [84], valley following [85], local maximum filtering, normalized cut [86], clustering-based algorithms [87], adaptive mean shift [88], and a number of other methods, e.g., segmentation based on spacing threshold and horizontal profile of the tree shape [89]. Hamraz, Contreras, and Zhang [90] propose a new robust algorithm for segmentation of individual trees in deciduous forest. Its overall accuracy was $77 \%$ and was not affected with different terrain and stand metrics. Another novel algorithm is proposed by Liu, Im, and Quackenbush [91]. For refinement boundaries between crowns detected by watershed algorithm, they developed Fishing Net Dragging 
algorithm. Detected boundaries were classified as boundaries between trees or between branches of a single tree using Random Forest machine learning. The accuracy of this approach reached $74 \%$ and $78 \%$ for deciduous and mixed forest stand. A segmentation algorithm based on hierarchical structuring of graph partitions representing structural components of tree crowns was proposed by Strîmbu and Strîmbu [92] who report overall accuracy of 99\%, 92\%, and 75\% in three forest areas with increasing complexity. The fact that detection rates depend on forest structure and tree status was confirmed by Sačkov et al. [93] who demonstrated the difference for tree classes: for dominant trees, the detection rate in their study was $66 \%$, for codominiant $48 \%$, for intermediate $18 \%$, and only $5 \%$ for suppressed trees.

No complex comparison of all presented algorithms has been performed. Vahukonen et al. [94] performed comparison of six algorithms and concluded that the performance of algorithms is more influenced by forest structure than by the algorithms themselves. However, Barnes et al. [84] indicated that watershed algorithms performed significantly better than the region-growing algorithm, Jaskierniak et al. [86] prefer local maximum filtering over normalized cut algorithm. Comparison of five selected algorithms utilizing canopy data [95] favors adaptive mean shift algorithm with precision of $91 \%$.

Automated methods of tree crown delineation necessarily result in some poor delineations. Such crows would benefit from revision, which could improve any forest attribute calculated from crown shapes and sizes. Leckie, Walsworth, and Gougeon [96] presented a method for identification of poor isolations that should be corrected.

Due to the complex shapes of forest canopies, the omission and commission errors of individual tree segmentation based on CHM analysis remain relatively high (correct detection $70 \%-90 \%$ for best performing segmentation algorithms [84]). For more accurate segmentation it is necessary to incorporate information extracted from points representing tree stems. Ayrey et al. [97] proposed an approach based on layer stacking, which utilized the whole depth of forest point clouds. Due to the additional information, the algorithm was able to increase detection rate by $15 \%-30 \%$ compared to $\mathrm{CHM}$ based tree segmentation; the improved performance was pronounced above all in broadleaf or mixed stands with more complex CHM that does not allow for clear delineation of individual crowns.

An alternative approach is Trunk Detection-Aided Mean Shift Clustering Technique [95], where positions of trunks detected from vertical histograms serve as references for delineation of individual trees. Using this approach, authors were able to correctly detect more than $91 \%$ of trees with a positional accuracy significantly improved (positioning error reduced by $33 \%$ ) compared to CHM based algorithms.

To connect geometric and spectral information of individual trees for further analysis, aerial images can be aligned to airborne laser data at single tree level by matching treetops automatically extracted from both data sets [98].

\subsubsection{Assessing Forest and Tree Height and Inventory Attributes}

Forest attributes are calculated largely from structural information contained in 3D point clouds. Point clouds representing both tree crowns and ground surface allow deriving crown height model (CHM). CHM represents heights of trees in a forest stand and represents the main source for estimation of other forest attributes such as diameters, basal area, volumes, or biomass. Point clouds for deriving $\mathrm{CHM}$ and forest parameters can come from both ALS and DAP. For DAP-based forest attributes estimation, it is recommended to acquire aerial images during leaf-on season, because the leaf-off season images have a strong negative impact on estimations of deciduous forest attributes [57]. In contrast, for ALS-based models, data acquired under leaf-off conditions may provide slightly better predictions [82,99]. Sumnall, Hill, and Hinsley [100] recommend utilizing of both leaf-on and leaf-off datasets simultaneously for the best accuracy of forest variables.

Most of the published works utilize the area-based approach, which consider area as the unit of interest. The area-based approach generally includes estimates of forest variables on stand-level, 
per hectare values or mean tree attributes. The estimates are usually based on regression models where predictors are different metrics derived from $\mathrm{CHM}$ or point cloud structure. The area-based approach is generally applied on larger areas; Næsset et al. [101] mention that in inventories of large forest areas on regional scale, the error of above ground biomass ALS-based estimation can be reduced by $40 \%-60 \%$ compared to traditional inventory approach utilizing pure field survey based on terrestrial sample plots. Accuracy of area-based estimates illustrate recent studies. Bohlin et al. [57] reported relative RMSE ranging from $7.7 \%$ to $10.5 \%$ for mean height; from $12.0 \%$ to $17.8 \%$ for mean diameter; from $21.8 \%$ to $22.8 \%$ for stem volume; and from $17.7 \%$ to $21.1 \%$ for basal area, without any significant difference between DAP and ALS data. Puliti et al. [60] estimated total volume with relative RMSE of $13.4 \%$, and predicted species-specific volume with relative RMSE of $36.6 \%, 46.5 \%$, and $84.9 \%$ for spruce, pine, and deciduous species, respectively.

By contrast, tree based approach represents the forest inventory on individual tree level. The process includes individual tree detection, crown delineation and estimation of tree metrics from $\mathrm{CHM}$ or points representing the individual detected trees. The individual tree parameter estimations are based on regression models derived from individual tree-level field data. (Yao, Krzystek, and Heurich [102] carried out a complex process of tree extraction, classification and individual tree volume estimation from full-waveform ALS with relative RMSE of volume estimation $16 \%$. Another process of tree detection and tree-based estimation of tree height, diameter, and volume was demonstrated by Sačkov et al. [93]; they achieved relative RMSE of $8 \%, 22 \%$, and $46 \%$, respectively. Silva et al. [103] showed the possibility of automatic matching of the reference trees to LiDAR extracted trees, which can greatly improve the efficiency of development of regression models for individual tree metric estimations. Tree height, basal area and volume was predicted in a tree-level inventory of longleaf pine forest with RMSE 3\%, 59\%, and 8\%, respectively.

Penner et al. [63] and Peuhkurinen [104] showed an approach for deriving diameter class distribution from ALS data. The distribution information, if added to area-based inventories, helps to bridge the gap between area- and tree-based inventories.

Traditionally, stepwise regression techniques are used to select the most significant predictors from a number of available canopy metrics to obtain a statistical model with the highest coefficient of determination. However, Bouvier et al. [99] suggest a more rational approach utilizing a priori defined variables describing complementary aspects of 3D canopy structure (mean canopy height, variance of canopy height, gap fraction, variation of leaf area density). Hansen et al. [105] show that canopy density metrics and metrics of point representation of lower part of canopy may be better predictors of forest attributes than canopy height metrics. Silva et al. [106] utilized only two variables (height of the top of the canopy and the skewness of the vertical distribution of LiDAR points) as predictors in regression models predicting the total and commercial volumes of loblolly pine plantations with RMSE less than $8 \%$. Whatever predictors are used in the regression models, McRoberts et al. $[68,107]$ alert that big attention must be given to the effects of extrapolation of models beyond the range of variables used to parametrize the models.

For area-based approach, slow density LiDAR data are capable to provide reliable estimation of forest attributes. Treitz et al. [108] report that density of LiDAR points does not affect the accuracy of forest attributes estimation unless the density decreases under $0.5 \mathrm{pulses} / \mathrm{m}^{2}$. Jakubowski, Guo, and Kelly [109] divide forest parameters in two groups; metrics such as tree height, diameter, or basal area remain unaffected by decreasing pulse density down to $1 \mathrm{pulse} / \mathrm{m}^{2}$, while variables such as canopy cover or tree density are more sensitive.

Statistic regression models are created to predict forest attributes as basal area, volume, aboveground biomass, total biomass across a wide range of canopy structures, sites, or geographic locations [99].

It may be difficult to compare individual methods for deriving forest attributes, because the results are not determined only by the methods, but are strongly affected by many factors and performance of individual methods can significantly differ for different datasets [110]. The main factors are forest 
structure [94] or data acquisition parameters, such as model of sensor, flying altitude or laser pulse frequencies [111,112]. To correct such effects, theoretical models allowing to recompute the ALS metrics to unbiased values were developed [113].

If species-specific volumes predictions are required, the structural information derived from 3D point clouds can be completed with auxiliary optical data, such as aerial or satellite images. Kukkonen et al. [114] shows that the accuracy of species-specific volumes prediction is significantly improved using any type of optical data, mainly in red edge and near infrared bands. The better resolution of the optical data, the higher is the improvement of the result; simultaneously, the improvement is more enhanced for broadleaf species.

There are two options for assessment of temporal changes of forest attributes (e.g., biomass). Indirect methods estimate the variables separately from two ALS acquisitions and yield the change estimate as a difference of the two outputs. Direct methods utilize temporal differences of ALS metrics as the predictor for the change of forest attributes. It has been shown that the direct approach of temporal biomass change estimates from ALS data significantly reduces the prediction error compared to the indirect methods [70,115]. Skowronski et al. [116] developed models for direct estimation of biomass change with R-squared values $0.81,0.72$, and 0.68 for live, dead, and total biomass resulting in estimations with RMSEs of 2.0,9.3, and $1.0 \mathrm{Mg} \mathrm{ha}^{-1}$ year $^{-1}$, which outperformed the indirect method as well as the field-based estimation. However, contrary results report McRoberts et al. [107] who achieved higher precision using indirect approach. Tompalski et al. [117] utilized 3D point cloud datasets from 2008 to estimate top height, basal area and total volume, which subsequently served for fitting growth and yield models to predict the future development. The yield curves were validated using point cloud from 2015; the relative RMSE of height, basal area and volume was 13\%, 44\%, and $50 \%$ for predicted data.

Airborne laser data can serve for deriving volume of standing and lying deadwood-an overview of the current situation and presented methods can be found in Marchi, Pirotti, and Lingua [118]—or soil organic carbon of forest soil [119] Using a suitable regression model, ALS canopy metrics can be related also to number of other forest variables as leaf area index [120], gap fraction, or defoliation (R2 values 0.82-0.95) [121]. Tompalski et al. [122] used ALS data to improve estimates of site index, which lead to improved estimates of volume or biomass in forest stands.

\subsubsection{Species Classification}

Information about species composition is an important input for reasonable estimations of forest attributes, such as volume or biomass. Tompalski et al. [123] show that even a very coarse information of species composition can improve volume predictions from ALS data: even with 50\% error in species composition, species-specific volume estimations reached higher accuracy than generic (species-independent) volume estimations.

Automatic species classification from remote sensing is a challenging task. It has been shown, that species classification methods based on spectral information generally achieve better results than methods relying on structural information derived from ALS point clouds; Dalponte et al. [79] reports tree detection rate from ALS and hyperspectral data $49 \%$ and $28 \%$, respectively. Still, the inter-specific variation in spectral characteristics is high and the spectral signatures of individual species overlap [124]. Therefore, last attempts focus on combining both structural and spectral information to predict trees from different combinations of data sources.

Vauhkonen et al. [125] report promising results from an early experimental phase of tree species classification from hyperspectral LiDAR data, where 18 spruce and pine trees were classified with accuracies of $78 \%-97 \%$. Puliti et al. [60] classified tree species classes (spruce, pine, broadleaf) from aerial imagery. Both structural information derived from photogrammetric point clouds and spectral variables extracted from digital number values were used as predictors in their regression models. The models predicted dominant species with $79 \%$ accuracy and the species proportions were predicted with RMSE of $21 \%$. Shen and Cao [126] combined metrics from both ALS data and 
hyperspectral imagery to classify five tree species using Random Forest classifier. They report overall classification accuracy of $85 \%$ and mention, that the combination of ALS and hyperspectral data showed improved accuracy (the improvement of $0.4 \%-5.6 \%$ ) in comparison to only hyperspectral data based classification. The combination of ALS data and hyperspectral imagery was used also by Sommer et al. [127] for classifying 13 tree species. Using principal component analysis, they selected the 53 most significant spectral bands, which allowed a classification accuracy of $77 \%$, and with combination with ALS derived features the overall classification accuracy increased to 94\%. Axelsson, Lindberg, and Olsson [128] investigated the potential of multispectral ALS data for classification of ten different species. The combination of structural features and spectral information yielded accuracy of $77 \%$, while the highest accuracy of classification based on structural features was $43 \%$.

From structural-based approaches, it is worth to mention the work of Li, Hu, and Noland [129] who derived several species-specific 3D features describing internal structures of individual tree crowns in high density ALS data (90 points $\mathrm{m}^{-2}$ ). Four species, two of which were coniferous and two broadleaf, were automatically classified based on the selected features with overall accuracy of $78 \%$.

An interesting approach was proposed by Korpela et al. [130] who showed that directional reflectance anisotropy was to some extent species-specific. According to the idea, species could be identified based on how reflectance in aerial images changes when the viewing direction is altered. However, it was revealed that the intra-specific variation is too high and that the gain from directional signatures for species classification, which was expected from simulations to reach 1-3 percentage points, was in reality insignificant [131].

An overview of current approaches for classifying tree species is provided by Fassnacht et al. [4] who state that most of species-classification studies followed data-driven approach and very few ones focus on understanding the theoretical background of the problem. Therefore, many species classification approaches work under certain conditions and do not in other cases. It seems, that automatic classification into several distinct classes can be performed with reasonable accuracy, while identification of individual tree species maps in complex forests will require judicious use of human judgment and intervention [124] an overview is shown in Table 3.

Table 3. Accuracies of methods for species classification using aerial data. ALS: aerial laser scanner; DAP: digital aerial photogrammetry.

\begin{tabular}{ccccc}
\hline Study & Data & Method & Species & Accuracy \\
\hline$[125]$ & Hyperspectral ALS (lab conditions) & Regression & Spruce and pine; individuals & $78 \%-97 \%$ \\
{$[60]$} & DAP (3D + spectral) & Regression & 3 classes; dominant species & $79 \%$ \\
{$[126]$} & Hyperspectral imagery & Random Forest & 5 species; individual trees & $80 \%$ \\
{$[126]$} & Hyperspectral+ ALS & Random Forest & 5 species; individual trees \\
{$[127]$} & Hyperspectral imagery & PCA & 13 species & $75 \%$ \\
{$[127]$} & Hyperspectral + ALS & PCA & 13 species & $74 \%$ \\
{$[128]$} & ALS & Regression & 10 species & $43 \%$ \\
{$[128]$} & Multispectral ALS & Regression & 10 species & $77 \%$ \\
{$[129]$} & ALS & Linear discriminant analysis & 4 species \\
\hline
\end{tabular}

\subsubsection{Assessing Forest Health and Physiology Status}

The applications of aerial data for forest health monitoring mainly employ changes in spectral properties of stressed, infested, or dead trees. Above all, hyperspectral data appears a very useful tool for this purpose. Abdel-Rahman et al. [132] attempted to detect defoliated pine trees infested by sirex woodwasp in airborne hyperspectral data. To avoid misclassification, they needed to distinguish between sirex-induced defoliation and lightning damage. For classification in three classes:-healthy, sirex attacked, and lightning damaged - they utilized Random Forest and Support Vector Machines classifiers over all available hyperspectral bands with classification accuracy of $74 \%$, or over selected significant bands with accuracy of $78 \%$.

Similar approach, i.e., Support Vector Machine classifier over hyperspectral data, was used to detect bark-beetle infested trees [133]. The method allowed an accurate classification of dead trees; however, detection of infestation stages was problematic. The green-attacked class was heavily 
overestimated with commission error of $65 \%$. Lausch et al. [134] reported also the capability of airborne hyperspectral data to distinguish between healthy and green-attacked trees. The important spectral indicator for separating the two classes was found in the spectral range of 450-890 nm. However, their classification result gained only 64\% accuracy. Parsher and King [135] mapped dead wood in forest canopies irrespective on the cause of mortality. They utilized high resolution color infrared airborne imagery and with the direct detection approach they achieved $94 \%$ accuracy in validation site and $90 \%$ accuracy in control site.

Application of high spatial resolution RGB aerial imagery for forest health monitoring is reviewed in White [136] in the context of pine beetle context. Aerial imagery can serve both as tree-level information source and for calibration and validation of imagery with lower spatial resolution such as satellite images.

\subsection{Unmanned Aerial Vehicle (UAV) Data}

Utilization of UAVs has recently gained a lot of attention, both in academic sphere and practice in different fields. It appears to be a viable alternative for the traditional data acquisition comprising satellites and planes, due to a number of benefits, such as low cost, flexibility of use and capability of providing very high resolution data. An overview of possible UAV applications in forest research is presented in $[9,137]$.

Alike for the aerial data, there are two major source of structural data from UAV: digital aerial photogrammetry (DAP) and laser scanning. DAP is recently a very popular method, because it requires only a consumer-grade UAV equipped with a camera. The acquired imagery is processed using Structure from Motion (SfM) technique resulting in a 3D point cloud. Detailed methodology of UAV image acquisition and processing for 3D photogrammetric reconstruction of trees and forest stands was described by Gatziolis et al. [138] and Liesein et al. [139]; a detailed description of the SfM technique is provided by Westboy et al. [140]. UAV based laser scanning is a more difficult task and so far a few works presented UAV LiDAR data acquisition and processing. First UAV laser scanning for tree detection and forest attributes evaluation was carried out by Jaakola et al. [141,142]. They were able to create DEM and estimate tree heights, and they presented method to obtain biomass change from multitemporal LiDAR point cloud.

UAV point clouds both from DAP and LiDAR typically are substantially denser than those acquired by ALS. Increased point density can result in more continuous canopy representation and improved detection of canopy tops [143]. However, the quality of resulted 3D point cloud still depends on a set of flight parameters and camera settings [144].

On the stand level, the UAV 3D data can be supported by terrestrial data from either laser scanning [145] or terrestrial close-range photogrammetry [146] to get detailed information on single trees and structure of the forest in small scale.

\subsubsection{Plantations and Succession Monitoring}

Due to the unrivalled spatial resolution providing ground sampling distance often reaching sub centimeter level, UAV imagery represents a very suitable tool for individual seedling detection and regeneration succession monitoring.

Feduck, McDermid, and Castilla [147] evaluated the possibilities of ultra-high spatial resolution (ground sampling distance about $3 \mathrm{~mm}$ ) UAV images for detection of coniferous seedlings. Their approach was based only on spectral information derived from a standard RGB camera; using two vegetation indices, the Green-Red difference index and the Blue-Green difference index, for decision. They report no significant advantage of red-edge band over the visible spectra: the overall accuracy using RGB variables was 96\%, and with the addition of red-edge variables, it reached $97 \%$. The authors also propose utilization of sample based approach, which can save up to $80 \%$ of flying time; unfortunately, they do not compare final accuracies for both approaches. 
Goodbody et al. [148] combined both spectral information from RGB camera in the form of visible vegetation indices with structural information from DAP point clouds to detect and classify seedlings in forest stands of 5, 10, and 15 years since plantation. Performing object-based image analysis, they reached overall accuracy $86 \%-95 \%$ in classifying images into classes conifer, deciduous and ground.

Röder et al. [149] showed that small low-budget UAV equipped with an optical sensor could provide images capable for deriving digital surface model allowing detecting manually or automatically small individual trees of natural regeneration or standing deadwood even in stands with a complex structure of post-disturbed mountain forest. However, the detection rates were only $39 \%$ for individual trees and $18 \%$ for trees in groups, which is much lower than reported in even-aged forest plantations.

\subsubsection{Individual Tree Segmentation}

Most of the approaches for individual tree detection utilize interpretation of CHM derived from photogrammetric or LiDAR 3D point cloud using different algorithms, e.g., local-maxima [150] or watershed algorithm [151]. Recent algorithms of automatic detection of individual trees from CHM can achieve overall accuracy higher than $80 \%$ [150]. Compared to ALS, UAV data provides more geometrical details, which result in improved tree detection; that was demonstrated by Thiel and Schmullius [152] who reported detection rate in ALS 78\%, and in UAV DAP point cloud 93\%. Balsi et al. [153] utilized RANSAC algorithm followed by k-means clustering to detect and segment individual crowns from LiDAR data acquired with an UAV. They successfully applied the method on a plantation of hazel trees characterized by irregularly shaped crowns and no evident apex, as a model of broadleaf forest, which is a challenging task for tree detection algorithms.

UAV data can provide not only tree positions, but also canopy gaps, which can be related to the spatio-temporal dynamics of forest, such as harvesting or naturally induced tree death [154]. Patch metrics can be also a reliable predictor of understory parameters (such as density, development, and species diversity) or biodiversity variables of forest environment [155].

3D information derived from drone imagery can be used to automatically detect and directly measure tree stumps in post-harvest sites [156,157]. Using machine learning approach, Puliti et al. [156] were also able to detect root- and butt-rot on the stumps.

There are also methods allowing for identifying crown areas of individual trees directly from images. Such methods utilize morphological operations and image segmentation. Kang et al. [158] successfully utilized NIR imagery for segmenting individual trees with overall accuracy about $90 \%$. However, methods based only on image analysis can be affected e.g., by different light conditions in one image caused by local topography or varying forest structure.

\subsubsection{Forest and Tree Height Assessment}

Height of individual trees are easily obtained from CHM. Chen et al. [159] calculated heights of tree regeneration with heights mostly between 0 and $0.8 \mathrm{~m}$ with RMSE of about $0.3 \mathrm{~m}$, while Zarco-Tejada et al. [160] obtained RMSE of about $0.35 \mathrm{~m}$ (i.e., $11 \%$ ) for trees with total height between 1.1 and $4.3 \mathrm{~m}$. Panagiotidis et al. [161] acquired heights of mature forest with RMSE of about $3 \mathrm{~m}$ (i.e., $11 \%-19 \%$ ). In areas of denser vegetation, DAP derived $\mathrm{CHM}$ can be unreliable because of the low point density on ground. Chen et al. [159] and Mlambo et al [161] demonstrated that the DAP tended to underestimate vegetation height due to ground elevation overestimation. In contrast, Thiel and Schmullius [152] reported slightly greater heights in DAP compared to ALS. Miller et al. [162] therefore recommend combining UAV imagery with existing DTMs, LiDAR data or with ground control markers to improve the ground elevation estimate and eliminate the height bias. They also notice that it can be difficult to estimate heights on deciduous trees during leaf-off season due to a lack of clearly identifiable features in forest canopy [162,163]. A possible solution can be deriving CHM from a set of leaf-on and leaf-off point clouds, where the leaf-off point cloud provides a good reference of terrain data, while the leaf-on point cloud clearly defines the forest canopy [164]. 
High accuracy of canopy height models derived from UAV imagery allows also for measuring within-season tree height growth $[164,165]$ which was not possible with traditional ground-based measurements, which have typically low accuracy and are very labor-intensive. Karpina et al. [166] used UAV imagery for permanent monitoring of height growth of scots pine plantation. Using photogrammetric 3D reconstruction, they were able to estimate current heights with accuracy within $5 \mathrm{~cm}$. A combination of point clouds of different origin can be utilized for temporal change detection as well. Goodbody et al. [3] exploited a combination of ALS from 2013 and DAP from 2015 to estimate height and volume growth.

Unlike DAP, ALS can provide detailed structure of the lower parts of forest stands and allows to estimate crown base height. Wallace, Watson, and Lucier [167] used the estimates of crown base height to detect successfully pruning of individual stems from UAV laser data.

\subsubsection{Assessing Inventory Attributes}

In recent years, a number of works handled with possibilities of UAV data acquisition for forest inventories. In one of the first studies, Wallace et al. [168] described the use of a low cost laser scanner for data acquisition in forest inventory. The authors later compared LiDAR data with DAP data [169] concluding that despite the LiDAR data are more accurate over different canopy densities, DAP still represented adequate low-cost alternative. Later Puliti et al. [170] evaluated a small fixed wing UAV for acquisition of relevant inventory data. UAV data typically provide spatial resolution high enough to obtain forest attributes on tree level. However, Puliti et al. [170] used area-based approach to predict forest attributes as Lorey's mean height, stem number, basal area, or stem volume using regression with predictor variables computed from point cloud.

Direct measurement of DBH from photogrammetric point clouds is still very difficult. DBH can be assessed using allometric relations between $\mathrm{DBH}$ and directly measurable parameters, such as tree height or crown size. Because the relation between DBH and tree height is very weak $\left(\mathrm{r}^{2}=0.18\right)$, more accurate estimates of DBH can be obtained from relations between DBH and crown width $\left(\mathrm{r}^{2}=0.78\right)$ or crown area $\left(r^{2}=0.79\right)$ [171]. Such allometric relation are especially helpful in light-demanding species, where the relation between tree size and crown parameters is strong, while in shade-tolerant species the significance of crown variables for predicting tree size is weak [172].

Direct measurement of DBH was possible with the help of UAV-borne LiDAR data collection, because laser beams were able to penetrate the forest canopy and 3D points representing tree stems could be recorded [173]. The study showed that the RIEGL RiCOPTER equipped with VUX-1UAV laser scanner could provide 3D point cloud allowing for deriving DBH. Although not all the stems in a forest stand were sufficiently represented in the resulting point cloud, the results of DBH estimation were comparable to the estimates from terrestrial laser point clouds; with the RMSE of DBH estimation $4.2 \mathrm{~cm}$. UAV-based point clouds can be used for DBH estimation in deciduous forest if image collection is performed in the leaf-off period so that the stems are visible $[174,175]$. However, the DBH estimation error remains high.

Volume and biomass are estimated with area-based approach from canopy height metrics derived from 3D point clouds both LiDAR and DAP. While Miller et al. [162] found the mean canopy height as the strongest predictor for above-ground and total biomass, other studies recommend utilization of regression models based on maximum canopy height as the main predictor of biomass in sparse [176] or dense forest [177]. Both studies affirm that there is little difference between biomass estimated from DAP and LiDAR-based CHM, especially if DAP-based CHM is supported with a reference DTM.

Multitemporal data can be used to observe changes in forest stands even with the use of data from different sources (ALS and DAP). The study of Goodbody et al. [178] shows that it is not possible to compare or merge directly point clouds from ALS and photogrammetry. However, comparing estimations of forest attributes, as stand volume, can be reasonable. 


\subsubsection{Species Classification}

Structural data allowing detecting individual trees can be completed with spectral data for accessing more forest attributes. Recently comprehensive reviews have been published about acquisition of the spectral information using UAV sensors [8,179]. A great advantage of UAV imagery is that in contrast to history, nowadays, high resolution multispectral or hyperspectral imagery can be acquired by the researchers themselves and with higher frequency than in the past, when all imagery was provided by specialized companies. On the other hand, such data cannot efficiently be acquired for the whole extent of forest enterprise; the effective extent of detailed UAV data is limited to several stands. A study performed in southern Finland [180] demonstrated that the combination of UAV-based CHM and hyperspectral orthomosaic allowed to automatically detect and classify species in forest stands. From trees detected in CHM derived from high-resolution RGB data, $90 \%-97 \%$ were correctly classified as pine, spruce, birch, or larch. The use of hyperspectral imagery for identification of deciduous tree species reports also Mozgeris et al. [181]. The study compared several machine learning classifiers, the best of which achieved the accuracy of $51 \%-72 \%$ for six deciduous species. Although they used a manned ultra-light aircraft, they discuss also the usage of UAVs as carrier platforms for the hyperspectral scanner. Goodbody et al. [148] combined DAP structural data with spectral information contained in several spectral indices (Visible Vegetation Index, Normalized Green Red Difference Index, or Green Leaf Indices) to classify forest cover into conifer, deciduous and ground classes using Object-Based Images Analyses, they achieved very high level of accuracies ranging from $86 \%$ up to $95 \%$. Similar approach was used to distinguish between categories spruce, fir and beech in central European mixed forest [182] with overall accuracy reported 78.4\%.

A combination of multispectral data and 3D geometrical data as shown in Brovkina et al. [182] was also used in Tuominen et al. [183] for species classification. The authors used visible to near-infrared (VNIR) and short-wave infrared (SWIR) images together with optical based geometry data from SfM to discriminate 26 tree species. They tested two different algorithms: k-nearest neighbor method (k-NN), combined with a genetic algorithm and a Random Forest method and achieved accuracy of classification 0.823 for tree species and 0.869 for tree genus. Multispectral, textural, and in addition multi-temporal data were deployed for tree species classification in Gini et al. [184], Maximum Likelihood algorithm and principal component analysis were applied on individual bands, and the authors concluded that texture features produced and increase in accuracy when the values changed from $58 \%$ to $78 \%$ or $87 \%$. Very high (or sometimes referred to as ultra-high) resolution from UAVs brings problems related to shadows and related error in classification. This problem was addressed in [185] where the authors evaluated the impact of shadows on classification accuracy using the Maximum Likelihood and Support Vector Machine classifiers, including different sizes of pixels from 0.03 to 1 meter. They achieved an accuracy of $91.5 \%$ in classification of the shadows and concluded that Visible Atmospherically Resistant Index serves as very good shadow index.

\subsubsection{Assessing Forest Health and Physiology Status}

Unmanned aerial vehicles (UAVs) may represent a very suitable platform for forest health monitoring by providing data with very high temporal and spatial resolutions [186] and allowing the control of forest health and stress at the individual tree level [187]. Similar to previous levels mentioned in the previous two chapters (satellites and planes), the series of articles [5], [6,7] represents substantial information about forest health and its monitoring using remote sensing. Regarding newer works, Cardil, Vepakomma, and Brotons [188], for example, applied a supervised maximum likelihood classification on UAV-acquired RGB imagery to quantify defoliation of pine stands at the tree level. They reported possibility of deriving from UAV images high-accuracy (79\%) field-based infestation indexes comparable to those used by forest technicians.

Multi-spectral imagery collected from a UAV is useful for identifying physiological stress in mature plantation trees even during the early stages of tree stress. On a series of simulated disease outbreaks, it was found that physiological stress could be detected earliest in data from the red edge 
and near infrared bands. In contrast to previous findings, red edge data did not offer earlier detection of physiological stress than the near infrared data [186]. Accordingly, the near infrared zone as well as the red edge band can reveal stress caused by bark beetle infestation in Norway spruce trees [189].

Hyperspectral data are also of high interest for detecting trees attacked by bark beetle. Results of recent studies $[190,191]$ indicate that hyperspectral data both from aircraft and UAV platforms can help to identify infested trees whereas the UAV data provided more accurate results $(81 \%$ classification accuracy) than the aircraft data (73\%) due to the finer spatial resolution. In Zhang et al. [192] the hyperspectral UAV based scanner was used to assess defoliation. The authors compared three waveband selection algorithms and reported $95.32 \%$ accuracy of detection of damaged individual trees utilizing the best of the algorithms mentioned.

Another symptom of stressed trees might be a small temperature increase [193]. As indicated by the study, UAV-borne thermal sensors might be able to detect sub-degree temperature increases caused by stress or disease progression at tree level. However, the proposed method still incorporates difficulties caused by environmental factors.

NDVI together with 3D point cloud can be used to identify dead trees in a forest stand. NDVI can even be used for qualitative classification of indicators of health in Norway spruce trees, such as mechanical damage of tree stems and resin exudation caused by fungus infestation [182]. NDVI was used also by Lehmann et al. [194] to detect trees infested by splendor beetle. Their approach of object-based classification based on modified NDVI derived from color infra-red mosaics, distinguished five classes, i.e., healthy, infested and dead branches, other vegetation, and canopy gaps, with an overall Kappa index 0.77-0.81.

\section{Conclusions}

This article reviews more than 190 works related to remote sensing for forest management at the enterprise level. The remote sensing is a powerful tool for data acquisition for forest management in all seven defined areas of information need for management decision-making: stratification (delineation of homogeneous areas), regeneration or succession assessment, individual tree segmentation, height measurement, assessment of inventory variables as DBH, basal area, stocking, volume), tree species classification, and finally an assessment of tree health and physiology status together with dead tree detection. Possibilities of obtaining relevant information in each of these areas were evaluated on three different levels represented by three carrier types: satellites, airplanes and UAVs.

The suitability of data from different carrier undoubtedly depends on particular application. To the best of our knowledge there are no works describing delineation of homogeneous forest areas from UAV data; most likely due to its small extent in comparison with satellite and aerial data. At the opposite extreme, we found no works for individual tree delineation from satellite data, although individual tree delineation is extensively studied with the use of aerial and UAV data; however, there are studies for assessing tree count in forest stands utilizing area based approaches in satellite data. Most of the studies utilizing UAV data focus on tree-level information while application utilizing aerial and satellite data typically operate at area-based or pixel-based levels.

The best-described field is vegetation height assessment. Height of individual trees and forest stands can be directly measured with high accuracy in data of all three levels obtained by LiDAR, radar or optical sensors. Many works describe assessment of other inventory variables as volume, basal area, or $\mathrm{DBH}$, mostly derived indirectly from forest height or heights of individual trees. Knowledge of inventory attributes is crucial for planning of most important management intervention, especially harvest optimization and planning or thinning, and for logistic setup related to the intervention (road maintenance, transport optimization etc.). Species classification and health assessment are another fields successfully studied, though many authors reported difficulties and uncertainty even with the use of advanced sensors and combination of both structural and spectral information. Regarding species classification, trees can be successfully classified into a few classes (e.g., spruce, pine, and broadleaf), but still it is difficult to distinguish individual species in mixture. Main problems 
in species classification are caused by large variation within species and large variation of external conditions. However, in regular forest management activities, up-to-data species composition is not required on frequent basis; it usually is utilized for long term planning.

A surprisingly low number of works are dedicated to the assessment and evaluation of forest regeneration. The current state of regenerated stands is essential information for forest practitioners; evaluation of regeneration is regularly performed twice per year as a basis for decisions about the replacement of damaged seedlings and whether other protective steps should be performed. Previously mentioned classification of species in rapidly changing regenerated young stands is of high importance here. Remote sensing techniques could significantly reduce the costs of regeneration succession monitoring in practical forestry; therefore, more works developing suggested approaches in this area can be expected.

The highest ratio of studies relevant for forest enterprise rely on aerial data; which can be attributed to the typical extent of forest enterprise and level of detail of data required for decision making in practical forestry. However, applications of UAV as the newest and dynamically developed carrier of remote sensors can be expected to adopt a large portion of remote sensing application in near future, especially for example in young regenerated stands as mentioned before, where ultrahigh resolution imagery can enhance the accuracy. In order to ensure economic efficiency at the forest enterprise level, utilization of each of the studied carriers and sensors should be considered based on particular management challenge and its extent.

Author Contributions: Authors contributed to the work equally.

Funding: This research was funded by OP RDE, grant number CZ.02.1.01/0.0/0.0/15_003/0000433 (Building up an excellent scientific team and its spatiotechnical background focused on mitigation of the impact of climatic changes to forests from the level of a gene to the level of a landscape at the FFWS CULS Prague)" and "Ministry of Agriculture of the Czech Republic grant number QK1920458".

Conflicts of Interest: The authors declare no conflict of interest. The funders had no role in the design of the study; in the collection, analyses, or interpretation of data; in the writing of the manuscript, or in the decision to publish the results.

\section{References}

1. Kaya, A.; Bettinger, P.; Boston, K.; Akbulut, R.; Ucar, Z.; Siry, J.; Merry, K.; Cieszewski, C. Optimisation in Forest Management. Curr. For. Rep. 2016, 2, 1-17. [CrossRef]

2. White, J.C.; Coops, N.C.; Wulder, M.A.; Vastaranta, M.; Hilker, T.; Tompalski, P. Remote Sensing Technologies for Enhancing Forest Inventories: A Review. Can. J. Remote Sens. 2016, 42, 619-641. [CrossRef]

3. Goodbody, T.R.H.; Coops, N.C.; Marshall, P.; Tompalski, P.; Crawford, P. Unmanned aerial systems for precision forest inventory purposes a review and case study. For. Chron. 2017, 93, 71-81. [CrossRef]

4. Fassnacht, F.E.; Latifi, H.; Stereńczak, K.; Modzelewska, A.; Lefsky, M.; Waser, L.T.; Straub, C.; Ghosh, A. Review of studies on tree species classification from remotely sensed data. Remote Sens. Environ. 2016, 186, 64-87. [CrossRef]

5. Lausch, A.; Erasmi, S.; King, D.J.; Magdon, P.; Heurich, M. Understanding forest health with remote sensing-Part I-A review of spectral traits, processes and remote-sensing characteristics. Remote Sens. 2016, 8, 1029. [CrossRef]

6. Lausch, A.; Erasmi, S.; King, D.J.; Magdon, P.; Heurich, M. Understanding forest health with Remote sensing-Part II-A review of approaches and data models. Remote Sens. 2017, 9, 129. [CrossRef]

7. Lausch, A.; Borg, E.; Bumberger, J.; Dietrich, P.; Heurich, M.; Huth, A.; Jung, A.; Klenke, R.; Knapp, S.; Mollenhauer, H.; et al. Understanding forest health with remote sensing, Part III: Requirements for a scalable multi-source forest health monitoring network based on data science approaches. Remote Sens. 2018, 10, 1120. [CrossRef]

8. Adão, T.; Hruška, J.; Pádua, L.; Bessa, J.; Peres, E.; Morais, R.; Sousa, J. Hyperspectral Imaging: A Review on UAV-Based Sensors, Data Processing and Applications for Agriculture and Forestry. Remote Sens. 2017, 9, 1110. [CrossRef] 
9. Torresan, C.; Berton, A.; Carotenuto, F.; Di Gennaro, S.F.; Gioli, B.; Matese, A.; Miglietta, F.; Vagnoli, C.; Zaldei, A.; Wallace, L. Forestry applications of UAVs in Europe: A review. Int. J. Remote Sens. 2017, 38, 2427-2447. [CrossRef]

10. Colomina, I.; Molina, P. Unmanned aerial systems for photogrammetry and remote sensing: A review. ISPRS J. Photogramm. Remote Sens. 2014, 92, 79-97. [CrossRef]

11. Poso, S.; Häme, T.; Paananen, R. A method of estimating the stand characteristics of a forest compartment using satellite imagery. Silva Fenn. 1984, 18, 261-292. [CrossRef]

12. Nyyssönen, A. On the Estimation of the Growing Stock from Aerial Photographs. Commun. Inst. For. Fenn. 1957, 46, 1-57.

13. Evaraerts, J. The Use of Unmanned Aerial Vehicles (UAVs) for Remote Sensing and Mapping. Int. Arch. Photogramm. Remote Sens. Spat. Inf. Sci. 2008, XXXVII, 1187-1192.

14. Amon, P.; Riegl, U.; Rieger, P.; Pfennigbauer, M.; Laser, R.; Systems, M. UAV-based laser scanning to meet special challenges in lidar surveying. In Proceedings of the Geomatics Indaba, Johannesburg, South Africa, 11-13 August 2015; pp. 138-147.

15. Mandlburger, G.; Glira, P.; Pfeifer, N. UAS-borne Lidar for Mapping Complex Terrain and Vegetation Structure. GIM Int. 2015, 30-33.

16. Stempfhuber, W.; Buchholz, M. A precise, low-cost RTK GNSS system for UAV applications. In Proceedings of the 2011 ISPRS Zurich 2011 Workshop, Zurich, Switzerland, 14-16 September 2011; Volume XXXVIII, pp. 289-293.

17. Rieke, M.; Foerster, T.; Geipel, J.; Prinz, T. High-precision positioning and real-time data processing of UAV-systems. ISPRS Int. Arch. Photogramm. Remote Sens. Spat. Inf. Sci. 2012, XXXVIII-1, 119-124. [CrossRef]

18. Fassnacht, F.E.; Mangold, D.; Schäfer, J.; Immitzer, M.; Kattenborn, T.; Koch, B.; Latifi, H. Estimating stand density, biomass and tree species from very high resolution stereo-imagery-Towards an all-in-one sensor for forestry applications? Forestry 2017, 90, 613-631. [CrossRef]

19. Wallner, A.; Elatawneh, A.; Schneider, T.; Kindu, M.; Ossig, B.; Knoke, T. Remotely sensed data controlled forest inventory concept. Eur. J. Remote Sens. 2018, 51, 75-87. [CrossRef]

20. Poso, S.; Paananen, R.; Markku, S. Forest inventory by compartments using satellite imagery. Silva Fenn. 1987, 21, 69-94. [CrossRef]

21. McRoberts, R.E.; Wendt, D.G.; Nelson, M.D.; Hansen, M.H. Using a land cover classification based on satellite imagery to improve the precision of forest inventory area estimates. Remote Sens. Environ. 2002, 81, 36-44. [CrossRef]

22. McRoberts, R.E.; Nelson, M.D.; Wendt, D.G. Stratified estimation of forest area using satellite imagery, inventory data, and the k-Nearest Neighbors technique. Remote Sens. Environ. 2002, 82, 457-468. [CrossRef]

23. Elatawneh, A.; Wallner, A.; Manakos, I.; Schneider, T.; Knoke, T. Forest cover database updates using multi-seasonal rapideye data-storm event assessment in the Bavarian Forest National Park. Forests 2014, 5, 1284-1303. [CrossRef]

24. Bergen, K.M.; Dronova, I. Observing succession on aspen-dominated landscapes using a remote sensing-ecosystem approach. Landsc. Ecol. 2007, 22, 1395-1410. [CrossRef]

25. Kozak, J.; Estreguil, C.; Troll, M. Forest cover changes in the northern carpathians in the 20th century: A slow transition. J. Land Use Sci. 2007, 2, 127-146. [CrossRef]

26. Szostak, M.; Hawryło, P.; Piela, D. Using of Sentinel-2 images for automation of the forest succession detection. Eur. J. Remote Sens. 2018, 51, 142-149. [CrossRef]

27. Nomura, K.; Mitchard, E. More Than Meets the Eye: Using Sentinel-2 to Map Small Plantations in Complex Forest Landscapes. Remote Sens. 2018, 10, 1693. [CrossRef]

28. Chen, H.; Cloude, S.R.; Goodenough, D.G. Forest Canopy Height Estimation Using Tandem-X Coherence Data. IEEE J. Sel. Top. Appl. Earth Obs. Remote Sens. 2016, 9, 3177-3188. [CrossRef]

29. Lefsky, M.A.; Harding, D.J.; Keller, M.; Cohen, W.B.; Carabajal, C.C.; Del Bom Espirito-Santo, F.; Hunter, M.O.; de Oliveira, R. Estimates of forest canopy height and aboveground biomass using ICESat. Geophys. Res. Lett. 2005, 32, L22S02. [CrossRef]

30. Simard, M.; Pinto, N.; Fisher, J.B.; Baccini, A. Mapping forest canopy height globally with spaceborne lidar. J. Geophys. Res. 2011, 116, G04021. [CrossRef] 
31. Staben, G.; Lucieer, A.; Scarth, P. Modelling LiDAR derived tree canopy height from Landsat TM, ETM+ and OLI satellite imagery-A machine learning approach. Int. J. Appl. Earth Obs. Geoinf. 2018, 73, 666-681. [CrossRef]

32. Neigh, C.; Masek, J.; Bourget, P.; Cook, B.; Huang, C.; Rishmawi, K.; Zhao, F.; Neigh, C.S.R.; Masek, J.G.; Bourget, P.; et al. Deciphering the Precision of Stereo IKONOS Canopy Height Models for US Forests with G-LiHT Airborne LiDAR. Remote Sens. 2014, 6, 1762-1782. [CrossRef]

33. Piermattei, L.; Marty, M.; Karel, W.; Ressl, C.; Hollaus, M.; Ginzler, C.; Pfeifer, N. Impact of the Acquisition Geometry of Very High-Resolution Pléiades Imagery on the Accuracy of Canopy Height Models over Forested Alpine Regions. Remote Sens. 2018, 10, 1542. [CrossRef]

34. Badreldin, N.; Sanchez-Azofeifa, A. Estimating Forest Biomass Dynamics by Integrating Multi-Temporal Landsat Satellite Images with Ground and Airborne LiDAR Data in the Coal Valley Mine, Alberta, Canada. 2015, 9, 2832-2849. [CrossRef]

35. Hyyppä, J.; Hyyppä, H.; Inkinen, M.; Engdahl, M.; Linko, S.; Zhu, Y.H. Accuracy comparison of various remote sensing data sources in the retrieval of forest stand attributes. For. Ecol. Manag. 2000, 128, 109-120. [CrossRef]

36. Shamsoddini, A.; Trinder, J.C.; Turner, R. Pine plantation structure mapping using WorldView-2 multispectral image. Int. J. Remote Sens. 2013, 34, 3986-4007. [CrossRef]

37. Thenkabail, P.S.; Stucky, N.; Griscom, B.W.; Ashton, M.S.; Diels, J.; Van der Meer, B.; Enclona, E. Biomass estimations and carbon stock calculations in the oil palm plantations of African derived savannas using IKONOS data. Int. J. Remote Sens. 2004, 25, 5447-5472. [CrossRef]

38. Kayitakire, F.; Hamel, C.; Defourny, P. Retrieving forest structure variables based on image texture analysis and IKONOS-2 imagery. Remote Sens. Environ. 2006, 102, 390-401. [CrossRef]

39. Ozdemir, I. Estimating stem volume by tree crown area and tree shadow area extracted from pan-sharpened Quickbird imagery in open Crimean juniper forests. Int. J. Remote Sens. 2008, 29, 5643-5655. [CrossRef]

40. Immitzer, M.; Stepper, C.; Böck, S.; Straub, C.; Atzberger, C. Use of WorldView-2 stereo imagery and National Forest Inventory data for wall-to-wall mapping of growing stock. For. Ecol. Manag. 2016, 359, 232-246. [CrossRef]

41. Awad, M.M. Forest mapping: A comparison between hyperspectral and multispectral images and technologies. J. For. Res. 2018, 29, 1395-1405. [CrossRef]

42. Mahdianpari, M.; Salehi, B.; Rezaee, M.; Mohammadimanesh, F.; Zhang, Y. Very deep convolutional neural networks for complex land cover mapping using multispectral remote sensing imagery. Remote Sens. 2018, 10, 1119. [CrossRef]

43. Pu, R.; Landry, S.; Yu, Q. Assessing the potential of multi-seasonal high resolution Pléiades satellite imagery for mapping urban tree species. Int. J. Appl. Earth Obs. Geoinf. 2018, 71, 144-158. [CrossRef]

44. Liu, Y.; Gong, W.; Hu, X.; Gong, J. Forest type identification with Random Forest using Sentinel-1A, Sentinel-2A, multi-temporal Landsat-8 and DEM data. Remote Sens. 2018, 10, 946. [CrossRef]

45. Bolyn, C.; Michez, A.; Gaucher, P.; Lejeune, P.; Bonnet, S. Forest mapping and species composition using supervised per pixel classification of Sentinel-2 imagery. Biotechnol. Agron. Soc. Environ. 2018, 22, 172-187.

46. Verde, N.; Mallinis, G.; Tsakiri-Strati, M.; Georgiadis, C.; Patias, P. Assessment of radiometric resolution impact on remote sensing data classification accuracy. Remote Sens. 2018, 10, 1267. [CrossRef]

47. Persson, M.; Lindberg, E.; Reese, H. Tree Species Classification with Multi-Temporal Sentinel-2 Data. Remote Sens. 2018, 10, 1794. [CrossRef]

48. Olsson, P.-O.; Lindström, J.; Eklundh, L. Near real-time monitoring of insect induced defoliation in subalpine birch forests with MODIS derived NDVI. Remote Sens. Environ. 2016, 181, 42-53. [CrossRef]

49. Meng, J.; Li, S.; Wang, W.; Liu, Q.; Xie, S.; Ma, W. Mapping forest health using spectral and textural information extracted from SPOT-5 satellite images. Remote Sens. 2016, 8, 719. [CrossRef]

50. Hawryło, P.; Bednarz, B.; Wężyk, P.; Szostak, M. Estimating defoliation of Scots pine stands using machine learning methods and vegetation indices of Sentinel-2. Eur. J. Remote Sens. 2018, 51, 194-204. [CrossRef]

51. Hart, S.J.; Veblen, T.T. Detection of spruce beetle-induced tree mortality using high- and medium-resolution remotely sensed imagery. Remote Sens. Environ. 2015, 168, 134-145. [CrossRef]

52. Byer, S.; Jin, Y. Detecting drought-induced tree mortality in Sierra Nevada forests with time series of satellite data. Remote Sens. 2017, 9, 929. [CrossRef] 
53. Baker, E.H.; Painter, T.H.; Schneider, D.; Meddens, A.J.H.; Hicke, J.A.; Molotch, N.P. Quantifying insect-related forest mortality with the remote sensing of snow. Remote Sens. Environ. 2017, 188, 26-36. [CrossRef]

54. Recanatesi, F.; Giuliani, C.; Ripa, M.; Recanatesi, F.; Giuliani, C.; Ripa, M.N. Monitoring Mediterranean Oak Decline in a Peri-Urban Protected Area Using the NDVI and Sentinel-2 Images: The Case Study of Castelporziano State Natural Reserve. Sustainability 2018, 10, 3308. [CrossRef]

55. Baltsavias, E.; Gruen, A.; Eisenbeiss, H.; Zhang, L.; Waser, L.T. High-quality image matching and automated generation of 3D tree models. Int. J. Remote Sens. 2008, 29, 1243-1259. [CrossRef]

56. Vastaranta, M.; Wulder, M.A.; White, J.C.; Pekkarinen, A.; Tuominen, S.; Ginzler, C.; Kankare, V.; Holopainen, M.; Hyyppä, J.; Hyyppä, H. Airborne laser scanning and digital stereo imagery measures of forest structure: Comparative results and implications to forest mapping and inventory update. Can. J. Remote Sens. 2013, 39, 382-395. [CrossRef]

57. Bohlin, J.; Bohlin, I.; Jonzén, J.; Nilsson, M. Mapping forest attributes using data from stereophotogrammetry of aerial images and field data from the national forest inventory. Silva Fenn. 2017, 51, 1-18. [CrossRef]

58. Gobakken, T.; Bollandsås, O.M.; Næsset, E. Comparing biophysical forest characteristics estimated from photogrammetric matching of aerial images and airborne laser scanning data. Scand. J. For. Res. 2015, 30, 73-86. [CrossRef]

59. Hernández-Clemente, R.; Navarro-Cerrillo, R.M.; Romero Ramírez, F.J.; Hornero, A.; Zarco-Tejada, P.J. A novel methodology to estimate single-tree biophysical parameters from 3D digital imagery compared to aerial laser scanner data. Remote Sens. 2014, 6, 11627-11648. [CrossRef]

60. Puliti, S.; Gobakken, T.; Ørka, H.O.; Næsset, E. Assessing 3D point clouds from aerial photographs for species-specific forest inventories. Scand. J. For. Res. 2017, 32, 68-79. [CrossRef]

61. White, J.C.; Stepper, C.; Tompalski, P.; Coops, N.C.; Wulder, M.A. Comparing ALS and image-based point cloud metrics and modelled forest inventory attributes in a complex coastal forest environment. Forests 2015, 6, 3704-3732. [CrossRef]

62. White, J.C.; Tompalski, P.; Coops, N.C.; Wulder, M.A. Comparison of airborne laser scanning and digital stereo imagery for characterizing forest canopy gaps in coastal temperate rainforests. Remote Sens. Environ. 2018, 208, 1-14. [CrossRef]

63. Penner, M.; Woods, M.; Pitt, D.G. A comparison of airborne laser scanning and image point cloud derived tree size class distribution models in Boreal Ontario. Forests 2015, 6, 4034-4054. [CrossRef]

64. Ota, T.; Ogawa, M.; Shimizu, K.; Kajisa, T.; Mizoue, N.; Yoshida, S.; Takao, G.; Hirata, Y.; Furuya, N.; Sano, T.; et al. Aboveground biomass estimation using structure from motion approach with aerial photographs in a seasonal tropical forest. Forests 2015, 6, 3882-3898. [CrossRef]

65. White, J.C.; Wulder, M.A.; Vastaranta, M.; Coops, N.C.; Pitt, D.; Woods, M. The utility of image-based point clouds for forest inventory: A comparison with airborne laser scanning. Forests 2013, 4, 518-536. [CrossRef]

66. Holopainen, M.; Wang, G. The calibration of digitized aerial photographs for forest stratification. Int. J. Remote Sens. 1998, 19, 677-696. [CrossRef]

67. Maltamo, M.; Ørka, H.O.; Bollandsås, O.M.; Gobakken, T.; Næsset, E. Using pre-classification to improve the accuracy of species-specific forest attribute estimates from airborne laser scanner data and aerial images. Scand. J. For. Res. 2015, 30, 336-345. [CrossRef]

68. McRoberts, R.E.; Gobakken, T.; Næsset, E. Post-stratified estimation of forest area and growing stock volume using lidar-based stratifications. Remote Sens. Environ. 2012, 125, 157-166. [CrossRef]

69. Næsset, E.; Gobakken, T.; Solberg, S.; Gregoire, T.G.; Nelson, R.; Ståhl, G.; Weydahl, D. Model-assisted regional forest biomass estimation using LiDAR and InSAR as auxiliary data: A case study from a boreal forest area. Remote Sens. Environ. 2011, 115, 3599-3614. [CrossRef]

70. Næsset, E.; Bollandsås, O.M.; Gobakken, T.; Gregoire, T.G.; Ståhl, G. Model-assisted estimation of change in forest biomass over an 11year period in a sample survey supported by airborne LiDAR: A case study with post-stratification to provide "activity data". Remote Sens. Environ. 2013, 128, 299-314. [CrossRef]

71. Bruggisser, M.; Hollaus, M.; Wang, D.; Pfeifer, N.; Bruggisser, M.; Hollaus, M.; Wang, D.; Pfeifer, N. Adaptive Framework for the Delineation of Homogeneous Forest Areas Based on LiDAR Points. Remote Sens. 2019, 11, 189. [CrossRef] 
72. Pouliot, D.A.; King, D.J.; Bell, F.W.; Pitt, D.G. Automated tree crown detection and delineation in high-resolution digital camera imagery of coniferous forest regeneration. Remote Sens. Environ. 2002, 82, 322-334. [CrossRef]

73. Gobakken, T.; Næsset, E.; Thieme, N.; Bollandsa, O.M. Detection of small single trees in the forest tundra ecotone using height values from airborne laser scanning. Can. J. Remote Sens. 2011, 37, 264-274.

74. Hauglin, M.; Næsset, E. Detection and Segmentation of Small Trees in the Forest-Tundra Ecotone Using Airborne Laser Scanning. Remote Sens. 2016, 8, 407. [CrossRef]

75. Stumberg, N.; Bollandsås, O.M.; Gobakken, T.; Næsset, E. Automatic detection of small single trees in the forest-tundra ecotone using airborne laser scanning. Remote Sens. 2014, 6, 10152-10170. [CrossRef]

76. Yao, W.; Krzystek, P.; Heurich, M. Enhanced detection of 3D individual trees in forested areas using airborne full-waveform LiDAR data by combining normalized cuts with spatial density clustering. ISPRS Ann. Photogramm. Remote Sens. Spat. Inf. Sci. 2013, 2, 349-354. [CrossRef]

77. Amiri, N.; Yao, W.; Heurich, M.; Krzystek, P.; Skidmore, A.K. Estimation of regeneration coverage in a temperate forest by 3D segmentation using airborne laser scanning data. Int. J. Appl. Earth Obs. Geoinf. 2016, 52, 252-262. [CrossRef]

78. Larsen, M.; Eriksson, M.; Descombes, X.; Perrin, G.; Brandtberg, T.; Gougeon, F.A. Comparison of six individual tree crown detection algorithms evaluated under varying forest conditions. Int. J. Remote Sens. 2011, 32, 5827-5852. [CrossRef]

79. Dalponte, M.; Ørka, H.O.; Ene, L.T.; Gobakken, T.; Næsset, E. Tree crown delineation and tree species classification in boreal forests using hyperspectral and ALS data. Remote Sens. Environ. 2014, 140, 306-317. [CrossRef]

80. Duan, Z.; Zhao, D.; Zeng, Y.; Zhao, Y.; Wu, B.; Zhu, J. Assessing and correcting topographic effects on forest canopy height retrieval using airborne LiDAR data. Sensors 2015, 15, 12133-12155. [CrossRef]

81. Ørka, H.O.; Bollandsås, O.M.; Hansen, E.H.; Næsset, E.; Gobakken, T. Effects of terrain slope and aspect on the error of ALS-based predictions of forest attributes. For. Int. J. For. Res. 2018, 91, 225-237. [CrossRef]

82. Gatziolis, D.; Fried, J.S.; Monleon, V.S. Challenges to estimating tree height via LiDAR in closed-canopy forests: A parable from western Oregon. For. Sci. 2010, 56, 139-155.

83. Maguya, A.S.; Junttila, V.; Kauranne, T. Algorithm for extracting digital terrain models under forest canopy from airborne LiDAR data. Remote Sens. 2014, 6, 6524-6548. [CrossRef]

84. Barnes, C.; Balzter, H.; Barrett, K.; Eddy, J.; Milner, S.; Suárez, J.C. Individual Tree Crown Delineation from Airborne Laser Scanning for Diseased Larch Forest Stands. Remote Sens. 2017, 9, 231. [CrossRef]

85. Ke, Y.; Quackenbush, L.J. A comparison of three methods for automatic tree crown detection and delineation from high spatial resolution imagery. Int. J. Remote Sens. 2011, 32, 3625-3647. [CrossRef]

86. Jaskierniak, D.; Kuczera, G.; Benyon, R.; Wallace, L. Using tree detection algorithms to predict stand sapwood area, basal area and stocking density in Eucalyptus regnans forest. Remote Sens. 2015, 7, 7298-7323. [CrossRef]

87. Gupta, S.; Weinacker, H.; Koch, B. Comparative analysis of clustering-based approaches for 3-D single tree detection using airborne fullwave LIDAR data. Remote Sens. 2010, 2, 968-989. [CrossRef]

88. Hu, X.; Chen, W.; Xu, W. Adaptive mean shift-based identification of individual trees using airborne LiDAR data. Remote Sens. 2017, 9, 148. [CrossRef]

89. Li, W.; Guo, Q.; Jakubowski, M.K.; Kelly, M. A New Method for Segmenting Individual Trees from the Lidar Point Cloud. Photogramm. Eng. Remote Sens. 2012, 78, 75-84. [CrossRef]

90. Hamraz, H.; Contreras, M.A.; Zhang, J. A robust approach for tree segmentation in deciduous forests using small-footprint airborne LiDAR data. Comput. Geosci. 2017, 102, 139-147. [CrossRef]

91. Liu, T.; Im, J.; Quackenbush, L.J. A novel transferable individual tree crown delineation model based on Fishing Net Dragging and boundary classification. ISPRS J. Photogramm. Remote Sens. 2015, 110, 34-47. [CrossRef]

92. Strîmbu, V.F.; Strîmbu, B.M. A graph-based segmentation algorithm for tree crown extraction using airborne LiDAR data. ISPRS J. Photogramm. Remote Sens. 2015, 104, 30-43. [CrossRef]

93. Sačkov, I.; Santopuoli, G.; Bucha, T.; Lasserre, B.; Marchetti, M. Forest inventory attribute prediction using lightweight aerial scanner data in a selected type of multilayered deciduous forest. Forests 2016, 7, 307. [CrossRef] 
94. Vauhkonen, J.; Ene, L.; Gupta, S.; Heinzel, J.; Holmgren, J.; Pitkänen, J.; Solberg, S.; Wang, Y.; Weinacker, H.; Hauglin, K.M.; et al. Comparative testing of single-tree detection algorithms under different types of forest. Forestry 2012, 85, 27-40. [CrossRef]

95. Chen, W.; Hu, X.; Chen, W.; Hong, Y.; Yang, M. Airborne LiDAR remote sensing for individual tree forest inventory using trunk detection-aided mean shift clustering techniques. Remote Sens. 2018, 10, 1078. [CrossRef]

96. Leckie, D.G.; Walsworth, N.; Gougeon, F.A. Identifying tree crown delineation shapes and need for remediation on high resolution imagery using an evidence based approach. ISPRS J. Photogramm. Remote Sens. 2016, 114, 206-227. [CrossRef]

97. Ayrey, E.; Fraver, S.; Kershaw, J.A.; Kenefic, L.S.; Hayes, D.; Weiskittel, A.R.; Roth, B.E. Layer Stacking: A Novel Algorithm for Individual Forest Tree Segmentation from LiDAR Point Clouds. Can. J. Remote Sens. 2017, 43, 16-27. [CrossRef]

98. Lee, J.-H.; Biging, G.S.; Fisher, J.B. An Individual Tree-Based Automated Registration of Aerial Images to LiDAR Data in a Forested Area. Photogramm. Eng. Remote Sens. 2016, 82, 699-710. [CrossRef]

99. Bouvier, M.; Durrieu, S.; Fournier, R.A.; Renaud, J.P. Generalizing predictive models of forest inventory attributes using an area-based approach with airborne LiDAR data. Remote Sens. Environ. 2015, 156, 322-334. [CrossRef]

100. Sumnall, M.J.; Hill, R.A.; Hinsley, S.A. Comparison of small-footprint discrete return and full waveform airborne lidar data for estimating multiple forest variables. Remote Sens. Environ. 2016, 173, $214-223$. [CrossRef]

101. Næsset, E.; Gobakken, T.; Bollandsås, O.M.; Gregoire, T.G.; Nelson, R.; Ståhl, G. Comparison of precision of biomass estimates in regional field sample surveys and airborne LiDAR-assisted surveys in Hedmark County, Norway. Remote Sens. Environ. 2013, 130, 108-120. [CrossRef]

102. Yao, W.; Krzystek, P.; Heurich, M. Tree species classification and estimation of stem volume and DBH based on single tree extraction by exploiting airborne full-waveform LiDAR data. Remote Sens. Environ. 2012, 123, 368-380. [CrossRef]

103. Silva, C.A.; Hudak, A.T.; Vierling, L.A.; Loudermilk, E.L.; O’Brien, J.J.; Hiers, J.K.; Jack, S.B.; Gonzalez-Benecke, C.; Lee, H.; Falkowski, M.J.; et al. Imputation of Individual Longleaf Pine (Pinus palustris Mill.) Tree Attributes from Field and LiDAR Data. Can. J. Remote Sens. 2016, 42, 554-573. [CrossRef]

104. Peuhkurinen, J.; Tokola, T.; Plevak, K.; Sirparanta, S.; Kedrov, A.; Pyankov, S. Predicting Tree Diameter Distributions from Airborne Laser Scanning, SPOT 5 Satellite, and Field Sample Data in the Perm Region, Russia. Forests 2018, 9, 639. [CrossRef]

105. Hansen, E.H.; Gobakken, T.; Bollandsås, O.M.; Zahabu, E.; Næsset, E. Modeling aboveground biomass in dense tropical submontane rainforest using airborne laser scanner data. Remote Sens. 2015, 7, 788-807. [CrossRef]

106. Silva, C.A.; Klauberg, C.; Hudak, A.T.; Vierling, L.A.; Jaafar, W.S.W.M.; Mohan, M.; Garcia, M.; Ferraz, A.; Cardil, A.; Saatchi, S. Predicting stem total and assortment volumes in an industrial Pinus taeda L. forest plantation using airborne laser scanning data and Random Forest. Forests 2017, 8, 254. [CrossRef]

107. McRoberts, R.E.; Næsset, E.; Gobakken, T.; Bollandsås, O.M. Indirect and direct estimation of forest biomass change using forest inventory and airborne laser scanning data. Remote Sens. Environ. 2015, 164, 36-42. [CrossRef]

108. Treitz, P.; Lim, K.; Woods, M.; Pitt, D.; Nesbitt, D.; Etheridge, D. LiDAR sampling density for forest resource inventories in Ontario, Canada. Remote Sens. 2012, 4, 830-848. [CrossRef]

109. Jakubowski, M.K.; Guo, Q.; Kelly, M. Tradeoffs between lidar pulse density and forest measurement accuracy. Remote Sens. Environ. 2013, 130, 245-253. [CrossRef]

110. Maltamo, M.; Bollandsås, O.M.; Vauhkonen, J.; Breidenbach, J.; Gobakken, T.; Næsset, E. Comparing different methods for prediction of mean crown height in Norway spruce stands using airborne laser scanner data. Forestry 2010, 83, 257-268. [CrossRef]

111. Næsset, E. Effects of different sensors, flying altitudes, and pulse repetition frequencies on forest canopy metrics and biophysical stand properties derived from small-footprint airborne laser data. Remote Sens. Environ. 2009, 113, 148-159. [CrossRef] 
112. Næsset, E. Vertical height errors in digital terrain models derived from airborne laser scanner data in a boreal-alpine ecotone in Norway. Remote Sens. 2015, 7, 4702-4725. [CrossRef]

113. Roussel, J.R.; Caspersen, J.; Béland, M.; Thomas, S.; Achim, A. Removing bias from LiDAR-based estimates of canopy height: Accounting for the effects of pulse density and footprint size. Remote Sens. Environ. 2017, 198, 1-16. [CrossRef]

114. Kukkonen, M.; Korhonen, L.; Maltamo, M.; Suvanto, A.; Packalen, P. How much can airborne laser scanning based forest inventory by tree species benefit from auxiliary optical data? Int. J. Appl. Earth Obs. Geoinf. 2018, 72, 91-98. [CrossRef]

115. Bollandsås, O.M.; Gregoire, T.G.; Næsset, E.; Øyen, B.H. Detection of biomass change in a Norwegian mountain forest area using small footprint airborne laser scanner data. Stat. Methods Appl. 2013, 22, 113-129. [CrossRef]

116. Skowronski, N.S.; Clark, K.L.; Gallagher, M.; Birdsey, R.A.; Hom, J.L. Airborne laser scanner-assisted estimation of aboveground biomass change in a temperate oak-pine forest. Remote Sens. Environ. 2014, 151, 166-174. [CrossRef]

117. Tompalski, P.; Coops, N.C.; Marshall, P.L.; White, J.C.; Wulder, M.A.; Bailey, T. Combining multi-date airborne laser scanning and digital aerial photogrammetric data for forest growth and yield modelling. Remote Sens. 2018, 10, 347. [CrossRef]

118. Marchi, N.; Pirotti, F.; Lingua, E. Airborne and terrestrial laser scanning data for the assessment of standing and lying deadwood: Current situation and new perspectives. Remote Sens. 2018, 10, 1356. [CrossRef]

119. Navarro-Cerrillo, R.M.; Duque-Lazo, J.; Rodríguez-Vallejo, C.; Varo-Martínez, M.; Palacios-Rodríguez, G. Airborne Laser Scanning Cartography of On-Site Carbon Stocks as a Basis for the Silviculture of Pinus Halepensis Plantations. Remote Sens. 2018, 10, 1660. [CrossRef]

120. Pearse, G.D.; Morgenroth, J.; Watt, M.S.; Dash, J.P. Optimising prediction of forest leaf area index from discrete airborne lidar. Remote Sens. Environ. 2017, 200, 220-239. [CrossRef]

121. Solberg, S. Mapping gap fraction, LAI and defoliation using various ALS penetration variables. Int. J. Remote Sens. 2010, 31, 1227-1244. [CrossRef]

122. Tompalski, P.; Coops, N.C.; White, J.C.; Wulder, M.A. Augmenting site index estimation with airborne laser scanning data. For. Sci. 2015, 61, 861-873. [CrossRef]

123. Tompalski, P.; Coops, N.C.; White, J.C.; Wulder, M.A. Simulating the impacts of error in species and height upon tree volume derived from airborne laser scanning data. For. Ecol. Manag. 2014, 327, 167-177. [CrossRef]

124. Leckie, D.G.; Gougeon, F.; McQueen, R.; Oddleifson, K.; Hughes, N.; Walsworth, N.; Gray, S. Production of a Large-Area Individual Tree Species Map for Forest Inventory in a Complex Forest Setting and Lessons Learned. Can. J. Remote Sens. 2017, 43, 140-167. [CrossRef]

125. Vauhkonen, J.; Hakala, T.; Suomalainen, J.; Kaasalainen, S.; Nevalainen, O.; Vastaranta, M.; Holopainen, M.; Hyyppä, J. Classification of Spruce and Pine Trees Using Active Hyperspectral LiDAR. IEEE Geosci. Remote Sens. Lett. 2013, 10, 1138-1141. [CrossRef]

126. Shen, X.; Cao, L. Tree-species classification in subtropical forests using airborne hyperspectral and LiDAR data. Remote Sens. 2017, 9, 1180. [CrossRef]

127. Sommer, C.; Holzwarth, S.; Heiden, U.; Heurich, M. Feature-Based Tree Species Classification Using Hyperspectral and Lidar Data. EARSeL eProc. 2015, 14, 49-70.

128. Axelsson, A.; Lindberg, E.; Olsson, H. Exploring multispectral ALS data for tree species classification. Remote Sens. 2018, 10, 183. [CrossRef]

129. Li, J.; Hu, B.; Noland, T.L. Classification of tree species based on structural features derived from high density LiDAR data. Agric. For. Meteorol. 2013, 171-172, 104-114. [CrossRef]

130. Korpela, I.; Heikkinen, V.; Honkavaara, E.; Rohrbach, F.; Tokola, T. Variation and directional anisotropy of reflectance at the crown scale-Implications for tree species classification in digital aerial images. Remote Sens. Environ. 2011, 115, 2062-2074. [CrossRef]

131. Korpela, I.; Mehtatalo, L.; Markelin, L.; Seppanen, A.; Kangas, A. Tree species identification in aerial image data using directional reflectance signatures. Silva Fenn. 2014, 48, 1087. [CrossRef]

132. Abdel-Rahman, E.M.; Mutanga, O.; Adam, E.; Ismail, R. Detecting Sirex noctilio grey-attacked and lightning-struck pine trees using airborne hyperspectral data, Random Forest and Support Vector Machines classifiers. ISPRS J. Photogramm. Remote Sens. 2014, 88, 48-59. [CrossRef] 
133. Fassnacht, F.E.; Latifi, H.; Ghosh, A.; Joshi, P.K.; Koch, B. Assessing the potential of hyperspectral imagery to map bark beetle-induced tree mortality. Remote Sens. Environ. 2014, 140, 533-548. [CrossRef]

134. Lausch, A.; Heurich, M.; Gordalla, D.; Dobner, H.J.; Gwillym-Margianto, S.; Salbach, C. Forecasting potential bark beetle outbreaks based on spruce forest vitality using hyperspectral remote-sensing techniques at different scales. For. Ecol. Manag. 2013, 308, 76-89. [CrossRef]

135. Pasher, J.; King, D.J. Mapping dead wood distribution in a temperate hardwood forest using high resolution airborne imagery. For. Ecol. Manag. 2009, 258, 1536-1548. [CrossRef]

136. White, J.C. Digital high spatial resolution aerial imagery to support forest health monitoring: The mountain pine beetle context. J. Appl. Remote Sens. 2012, 6, 062527. [CrossRef]

137. Tang, L.; Shao, G. Drone remote sensing for forestry research and practices. J. For. Res. 2015, 26, $791-797$. [CrossRef]

138. Gatziolis, D.; Lienard, J.F.; Vogs, A.; Strigul, N.S. 3D tree dimensionality assessment using photogrammetry and small unmanned aerial vehicles. PLoS ONE 2015, 10, e0137765. [CrossRef] [PubMed]

139. Lisein, J.; Pierrot-Deseilligny, M.; Bonnet, S.; Lejeune, P. A photogrammetric workflow for the creation of a forest canopy height model from small unmanned aerial system imagery. Forests 2013, 4, 922-944. [CrossRef]

140. Westoby, M.J.; Brasington, J.; Glasser, N.F.; Hambrey, M.J.; Reynolds, J.M. "Structure-from-Motion" photogrammetry: A low-cost, effective tool for geoscience applications. Geomorphology 2012, 179, 300-314. [CrossRef]

141. Jaakkola, A.; Hyyppä, J.; Kukko, A.; Yu, X.; Kaartinen, H.; Lehtomäki, M.; Lin, Y. A low-cost multi-sensoral mobile mapping system and its feasibility for tree measurements. ISPRS J. Photogramm. Remote Sens. 2010, 65, 514-522. [CrossRef]

142. Lin, Y.; Hyyppa, J.; Jaakkola, A. Mini-UAV-Borne LIDAR for Fine-Scale Mapping. IEEE Geosci. Remote Sens. Lett. 2011, 8, 426-430. [CrossRef]

143. Fankhauser, K.E.; Strigul, N.S.; Gatziolis, D. Augmentation of Traditional Forest Inventory and Airborne Laser Scanning with Unmanned Aerial Systems and Photogrammetry for Forest Monitoring. Remote Sens. 2018, 10, 1562. [CrossRef]

144. Dandois, J.P.; Olano, M.; Ellis, E.C. Optimal altitude, overlap, and weather conditions for computer vision uav estimates of forest structure. Remote Sens. 2015, 7, 13895-13920. [CrossRef]

145. Aicardi, I.; Dabove, P.; Lingua, A.; Piras, M. Integration between TLS and UAV photogrammetry techniques for forestry applications. iFor. Biogeosci. For. 2016, 10, 41-47. [CrossRef]

146. Mikita, T.; Janata, P.; Surový, P. Forest stand inventory based on combined aerial and terrestrial close-range photogrammetry. Forests 2016, 7, 165. [CrossRef]

147. Feduck, C.; McDermid, G.J.; Castilla, G. Detection of coniferous seedlings in UAV imagery. Forests 2018, 9, 462. [CrossRef]

148. Goodbody, T.R.H.; Coops, N.C.; Hermosilla, T.; Tompalski, P.; Crawford, P. Assessing the status of forest regeneration using digital aerial photogrammetry and unmanned aerial systems. Int. J. Remote Sens. 2018, 39, 5246-5264. [CrossRef]

149. Röder, M.; Latifi, H.; Hill, S.; Wild, J.; Svoboda, M.; Brůna, J.; Macek, M.; Nováková, M.H.; Gülch, E.; Heurich, M. Application of optical unmanned aerial vehicle-based imagery for the inventory of natural regeneration and standing deadwood in post-disturbed spruce forests. Int. J. Remote Sens. 2018, 39, 5288-5309. [CrossRef]

150. Mohan, M.; Silva, C.A.; Klauberg, C.; Jat, P.; Catts, G.; Cardil, A.; Hudak, A.T.; Dia, M. Individual tree detection from unmanned aerial vehicle (UAV) derived canopy height model in an open canopy mixed conifer forest. Forests 2017, 8, 340. [CrossRef]

151. Panagiotidis, D.; Abdollahnejad, A.; Surový, P.; Chiteculo, V. Determining tree height and crown diameter from high-resolution UAV imagery. Int. J. Remote Sens. 2017, 38, 2392-2410. [CrossRef]

152. Thiel, C.; Schmullius, C. Comparison of UAV photograph-based and airborne lidar-based point clouds over forest from a forestry application perspective. Int. J. Remote Sens. 2016, 38, 2411-2426. [CrossRef]

153. Balsi, M.; Esposito, S.; Fallavollita, P.; Nardinocchi, C. Single-tree detection in high-density LiDAR data from UAV-based survey. Eur. J. Remote Sens. 2018, 51, 679-692. [CrossRef]

154. Getzin, S.; Nuske, R.S.; Wiegand, K. Using unmanned aerial vehicles (UAV) to quantify spatial gap patterns in forests. Remote Sens. 2014, 6, 6988-7004. [CrossRef] 
155. Bagaram, M.; Giuliarelli, D.; Chirici, G.; Giannetti, F.; Barbati, A.; Bagaram, M.B.; Giuliarelli, D.; Chirici, G.; Giannetti, F.; Barbati, A. UAV Remote Sensing for Biodiversity Monitoring: Are Forest Canopy Gaps Good Covariates? Remote Sens. 2018, 10, 1397.

156. Puliti, S.; Talbot, B.; Astrup, R. Tree-Stump Detection, Segmentation, Classification, and Measurement Using Unmanned Aerial Vehicle (UAV) Imagery. Forests 2018, 9, 102. [CrossRef]

157. Samiappan, S.; Turnage, G.; McCraine, C.; Skidmore, J.; Hathcock, L.; Moorhead, R. Post-Logging Estimation of Loblolly Pine (Pinus taeda) Stump Size, Area and Population Using Imagery from a Small Unmanned Aerial System. Drones 2017, 1, 4. [CrossRef]

158. Kang, J.; Wang, L.; Chen, F.; Niu, Z. Identifying tree crown areas in undulating eucalyptus plantations using JSEG multi-scale segmentation and unmanned aerial vehicle near-infrared imagery. Int. J. Remote Sens. 2017, 38, 2296-2312. [CrossRef]

159. Chen, S.; McDermid, G.J.; Castilla, G.; Linke, J. Measuring vegetation height in linear disturbances in the boreal forest with UAV photogrammetry. Remote Sens. 2017, 9, 1257. [CrossRef]

160. Zarco-Tejada, P.J.; Diaz-Varela, R.; Angileri, V.; Loudjani, P. Tree height quantification using very high resolution imagery acquired from an unmanned aerial vehicle (UAV) and automatic 3D photo-reconstruction methods. Eur. J. Agron. 2014, 55, 89-99. [CrossRef]

161. Mlambo, R.; Woodhouse, I.H.; Gerard, F.; Anderson, K. Structure from motion (SfM) photogrammetry with drone data: A low cost method for monitoring greenhouse gas emissions from forests in developing countries. Forests 2017, 8, 68. [CrossRef]

162. Miller, E.; Dandois, J.P.; Detto, M.; Hall, J.S. Drones as a tool for monoculture plantation assessment in the steepland tropics. Forests 2017, 8, 168. [CrossRef]

163. Dandois, J.P.; Ellis, E.C. Remote sensing of vegetation structure using computer vision. Remote Sens. 2010, 2, 1157-1176. [CrossRef]

164. Dandois, J.P.; Ellis, E.C. High spatial resolution three-dimensional mapping of vegetation spectral dynamics using computer vision. Remote Sens. Environ. 2013, 136, 259-276. [CrossRef]

165. Dempewolf, J.; Nagol, J.; Hein, S.; Thiel, C.; Zimmermann, R. Measurement of within-season tree height growth in a mixed forest stand using UAV imagery. Forests 2017, 8, 231. [CrossRef]

166. Karpina, M.; Jarzabek-Rychard, M.; Tymków, P.; Borkowski, A. UAV-based automatic tree growth measurement for biomass estimation. In Proceedings of the International Archives of the Photogrammetry, Remote Sensing and Spatial Information Sciences, Prague, Czech Republic, 12-19 July 2016; Volume XLI-B8, pp. 685-688.

167. Wallace, L.; Watson, C.; Lucieer, A. Detecting pruning of individual stems using airborne laser scanning data captured from an Unmanned Aerial Vehicle. Int. J. Appl. Earth Obs. Geoinf. 2014, 30, 76-85. [CrossRef]

168. Wallace, L.; Lucieer, A.; Watson, C.; Turner, D. Development of a UAV-LiDAR system with application to forest inventory. Remote Sens. 2012, 4, 1519-1543. [CrossRef]

169. Wallace, L.; Lucieer, A.; Malenovský, Z.; Turner, D.; Vopěnka, P. Assessment of forest structure using two UAV techniques: A comparison of airborne laser scanning and structure from motion (SfM) point clouds. Forests 2016, 7, 62. [CrossRef]

170. Puliti, S.; Ørka, H.; Gobakken, T.; Næsset, E. Inventory of Small Forest Areas Using an Unmanned Aerial System. Remote Sens. 2015, 7, 9632-9654. [CrossRef]

171. Iizuka, K.; Yonehara, T.; Itoh, M.; Kosugi, Y. Estimating Tree Height and Diameter at Breast Height (DBH) from Digital surface models and orthophotos obtained with an unmanned aerial system for a Japanese Cypress (Chamaecyparis obtusa) Forest. Remote Sens. 2018, 10, 13. [CrossRef]

172. Zhang, J.; Hu, J.; Lian, J.; Fan, Z.; Ouyang, X.; Ye, W. Seeing the forest from drones: Testing the potential of lightweight drones as a tool for long-term forest monitoring. Biol. Conserv. 2016, 198, 60-69. [CrossRef]

173. Brede, B.; Lau, A.; Bartholomeus, H.M.; Kooistra, L. Comparing RIEGL RiCOPTER UAV LiDAR derived canopy height and DBH with terrestrial LiDAR. Sensors 2017, 17, 2371. [CrossRef] [PubMed]

174. Carr, J.C.; Slyder, J.B. Individual tree segmentation from a leaf-off photogrammetric point cloud. Int. J. Remote Sens. 2018, 39, 5195-5210. [CrossRef]

175. Fritz, A.; Kattenborn, T.; Koch, B. UAV-based photogrammetric point clouds-Tree stem mapping in open stands in comparison to terrestrial laser scanner point clouds. Int. Arch. Photogramm. Remote Sens. Spat. Inf. Sci. 2013, 40, 141-146. [CrossRef] 
176. Kachamba, D.J.; Ørka, H.O.; Gobakken, T.; Eid, T.; Mwase, W. Biomass estimation using 3D data from unmanned aerial vehicle imagery in a tropical woodland. Remote Sens. 2016, 8, 968. [CrossRef]

177. Messinger, M.; Asner, G.P.; Silman, M. Rapid assessments of amazon forest structure and biomass using small unmanned aerial systems. Remote Sens. 2016, 8, 615. [CrossRef]

178. Goodbody, T.R.H.; Coops, N.C.; Tompalski, P.; Crawford, P.; Day, K.J.K. Updating residual stem volume estimates using ALS- and UAV-acquired stereo-photogrammetric point clouds. Int. J. Remote Sens. 2016, 38, 2938-2953. [CrossRef]

179. Aasen, H.; Honkavaara, E.; Lucieer, A.; Zarco-Tejada, P.J. Quantitative remote sensing at ultra-high resolution with UAV spectroscopy: A review of sensor technology, measurement procedures, and data correctionworkflows. Remote Sens. 2018, 10, 1091. [CrossRef]

180. Nevalainen, O.; Honkavaara, E.; Tuominen, S.; Viljanen, N.; Hakala, T.; Yu, X.; Hyyppä, J.; Saari, H.; Pölönen, I.; Imai, N.N.; et al. Individual tree detection and classification with UAV-Based photogrammetric point clouds and hyperspectral imaging. Remote Sens. 2017, 9, 185. [CrossRef]

181. Mozgeris, G.; Jonikavičius, D.; Straigyt, L.; Gadal, S.; Ouerghemmi, W. Ultra-Light Aircraft-Based Hyperspectral and Colour-Infrared Imaging to Identify Deciduous Tree Species in an Urban Environment. Remote Sens. 2015, 10, 1668. [CrossRef]

182. Brovkina, O.; Cienciala, E.; Surový, P.; Janata, P. Unmanned aerial vehicles (UAV) for assessment of qualitative classification of Norway spruce in temperate forest stands. Geo-Spat. Inf. Sci. 2018, 5020, 12-20. [CrossRef]

183. Tuominen, S.; Näsi, R.; Honkavaara, E.; Balazs, A.; Hakala, T.; Viljanen, N.; Pölönen, I.; Saari, H.; Ojanen, H. Assessment of classifiers and remote sensing features of hyperspectral imagery and stereo-photogrammetric point clouds for recognition of tree species in a forest area of high species diversity. Remote Sens. 2018, 10, 714. [CrossRef]

184. Gini, R.; Sona, G.; Ronchetti, G.; Passoni, D.; Pinto, L. Improving Tree Species Classification Using UAS Multispectral Images and Texture Measures. ISPRS Int. J. Geo-Inform. 2018, 7, 315. [CrossRef]

185. Milas, A.S.; Arend, K.; Mayer, C.; Simonson, M.A.; Mackey, S. Different colours of shadows: Classification of UAV images. Int. J. Remote Sens. 2017, 38, 3084-3100. [CrossRef]

186. Dash, J.P.; Watt, M.S.; Pearse, G.D.; Heaphy, M.; Dungey, H.S. Assessing very high resolution UAV imagery for monitoring forest health during a simulated disease outbreak. ISPRS J. Photogramm. Remote Sens. 2017, 131, 1-14. [CrossRef]

187. Dash, J.; Pearse, G.; Watt, M. UAV Multispectral Imagery Can Complement Satellite Data for Monitoring Forest Health. Remote Sens. 2018, 10, 1216. [CrossRef]

188. Cardil, A.; Vepakomma, U.; Brotons, L. Assessing Pine Processionary Moth Defoliation Using Unmanned Aerial Systems. Forests 2017, 8, 402. [CrossRef]

189. Minařík, R.; Langhammer, J. Use of a multispectral UAV photogrammetry for detection and tracking of forest disturbance dynamics. Int. Arch. Photogramm. Remote Sens. Spat. Inf. Sci. 2016, 41, 711-718. [CrossRef]

190. Näsi, R.; Honkavaara, E.; Lyytikäinen-Saarenmaa, P.; Blomqvist, M.; Litkey, P.; Hakala, T.; Viljanen, N.; Kantola, T.; Tanhuanpää, T.; Holopainen, M. Using UAV-based photogrammetry and hyperspectral imaging for mapping bark beetle damage at tree-level. Remote Sens. 2015, 7, 15467-15493. [CrossRef]

191. Näsi, R.; Honkavaara, E.; Blomqvist, M.; Lyytikäinen-Saarenmaa, P.; Hakala, T.; Viljanen, N.; Kantola, T.; Holopainen, M. Remote sensing of bark beetle damage in urban forests at individual tree level using a novel hyperspectral camera from UAV and aircraft. Urban For. Urban Green. 2018, 30, 72-83. [CrossRef]

192. Zhang, N.; Zhang, X.; Yang, G.; Zhu, C.; Huo, L.; Feng, H. Assessment of defoliation during the Dendrolimus tabulaeformis Tsai et Liu disaster outbreak using UAV-based hyperspectral images. Remote Sens. Environ. 2018, 217, 323-339. [CrossRef]

193. Smigaj, M.; Gaulton, R.; Barr, S.L.; Suárez, J.C. Uav-Borne Thermal Imaging for Forest Health Monitoring: Detection of Disease-Induced Canopy Temperature Increase. ISPRS Int. Arch. Photogramm. Remote Sens. Spat. Inf. Sci. 2015, XL-3/W3, 349-354. [CrossRef]

194. Lehmann, J.R.K.; Nieberding, F.; Prinz, T.; Knoth, C. Analysis of unmanned aerial system-based CIR images in forestry-A new perspective to monitor pest infestation levels. Forests 2015, 6, 594-612. [CrossRef]

(C) 2019 by the authors. Licensee MDPI, Basel, Switzerland. This article is an open access article distributed under the terms and conditions of the Creative Commons Attribution (CC BY) license (http:/ / creativecommons.org/licenses/by/4.0/). 